\title{
Most Superficial Sublamina of Rat Superior Colliculus: Neuronal Response Properties and Correlates With Perceptual Figure-Ground Segregation
}

\author{
S. V. Girman ${ }^{1,2}$ and R. D. Lund ${ }^{1,2}$ \\ ${ }^{1}$ University of Utah, Salt Lake City, Utah; and ${ }^{2}$ Oregon Health and Science University, Portland, Oregon
}

Submitted 17 January 2007; accepted in final form 29 April 2007

\begin{abstract}
Girman SV, Lund RD. Most superficial sublamina of rat superior colliculus: neuronal response properties and correlates with perceptual figure-ground segregation. J Neurophysiol 98: 161-177, 2007. First published May 2, 2007; doi:10.1152/jn.00059.2007. The uppermost layer (stratum griseum superficiale, SGS) of the superior colliculus (SC) provides an important gateway from the retina to the visual extrastriate and visuomotor systems. The majority of attention has been given to the role of this "visual" SC in saccade generation and target selection and it is generally considered to be less important in visual perception. We have found, however, that in the rat SGS1, the most superficial division of the SGS, the neurons perform very sophisticated analysis of visual information. First, in studying their responses with a variety of flashing stimuli we found that the neurons respond not to brightness changes per se, but to the appearance and/or disappearance of visual shapes in their receptive fields (RFs). Contrary to conventional RFs of neurons at the early stages of visual processing, the RFs in SGS1 cannot be described in terms of fixed spatial distribution of excitatory and inhibitory inputs. Second, SGS1 neurons showed robust orientation tuning to drifting gratings and orientation-specific modulation of the center response from surround. These are features previously seen only in visual cortical neurons and are considered to be involved in "contour" perception and figureground segregation. Third, responses of SGS1 neurons showed complex dynamics; typically the response tuning became progressively sharpened with repetitive grating periods. We conclude that SGS1 neurons are involved in considerably more complex analysis of retinal input than was previously thought. SGS1 may participate in early stages of figure-ground segregation and have a role in low-resolution nonconscious vision as encountered after visual decortication.
\end{abstract}

\section{N T R O D U C T I O N}

The mammalian superior colliculus (SC) is a stratified multisensory integrative structure in which the complexity of sensory integration increases with depth. Retinal input to SC is densest in the stratum griseum superficiale (SGS), which exclusively processes visual information. The uppermost SGS sublamina, SGS1, contains the highest density of retinotectal terminals-but few, if any, cortical terminals - and is characterized by complex synaptic patterns including inhibitory dendrodendritic synapses (Cunningham and Lund 1971; Langer and Lund 1974; Lund 1969). Input from the visual cortical areas terminates in the deeper sublamina, SGS2, and in the stratum opticum, where the afferents from SGS1 and from retinal ganglion cells of different types from those innervating SGS1 also converge (Batista et al. 2003; Lee et al. 2001; Mize 1996; Nakajima et al. 1996). The SGS projects to the lateral geniculate nucleus and to the deeper layers of SC, which

Address for reprint requests and other correspondence: S. V. Girman, Oregon Health and Science University, Casey Eye Institute, 3375 SW Terwilliger Blvd, Portland, OR 97239 (E-mail: girmans@ohsu.edu). integrate visual, auditory, and somatosensory information (for review, see Stein et al. 2004) and generate motor commands for eye saccades and other attention-directed movements (for review, see Wurtz and Optican 1994). In addition, the SGS1 projects to the lateral posterior thalamic nucleus, thus conveying information to the extrastriate visual cortex in parallel with the retino-geniculo-striate pathway. Although the integrative role of the deep layers of the SC has been studied in great detail, essentially nothing is known about how cells in SGS1 process retinal input. As far as we aware, SGS1 and SGS2 have never been segregated on the ground of neuronal visual responses. Units throughout the SGS have been reported to be imprecisely tuned to specific stimulus parameters, responding to flashing uniform light spots, to both large and small stimuli, moving and stationary light spots, and have been thought to show little or no orientation specificity (see, e.g., Boyer et al. 2005). Preliminary studies led us to notice that units in the two sublayers behaved quite differently and that SGS1 neurons did not conform to the role of SGS neurons commonly seen in subserving reflexive saccade generation and target selection.

We have used the rat for these studies because there are already good descriptions of synaptic organization and biochemical specificity of different transmitters and receptors within SGS1 (for review see Binns 1999; Cirone and Salt 2001). Furthermore, visual processing in the rat has much in common with other mammals, including its neurophysiology (Girman et al. 1999), good behavioral visual shape discrimination (Lashley 1938), and ability to navigate in virtual reality (Holscher et al. 2005); in addition, operant behavior can be controlled by visual shapes presented on a computer display (Nekovarova and Klement 2006). Although only a few publications have been directly devoted to studying response properties of neurons throughout the rat SGS, these emphasize the ON, OFF, Or ON-OFF responses, with a silent suppressive surround, to stationary flashing spots, selectivity to direction and velocity of movement, and the lack of orientation selectivity (Fortin et al. 1999; Fukuda and Iwama 1978; Gonzalez et al. 1992), similar to those reported in golden hamster (Razak and Pallas 2005; Tiao and Blakemore 1976). Again, no distinction of differential response properties in SGS1 and SGS2 was noted, although occasional atypical cells have been reported (Tiao and Blakemore 1976).

A further reason for using the rat in the present study is that it serves as a model for inherited human retinal disease and has been used to assess potential therapeutic approaches that may be applicable clinically. We have found that recording from the

\footnotetext{
The costs of publication of this article were defrayed in part by the payment of page charges. The article must therefore be hereby marked "advertisement" in accordance with 18 U.S.C. Section 1734 solely to indicate this fact.
} 
SC yields valuable data in evaluating efficacy of specific manipulations applied to the degenerating retina (Girman et al. 2005) and, as such, it is important to know further details of response properties of this region.

Here we have expanded on our early studies reported in abstract form (Girman and Lund 2005a,b, 2006) with the object of learning more about the intricacy of visual processing in the SGS1 sublayer. In addition to flashing and moving light spots, traditionally used to study response properties in the SC, we used a broader stimulus set including drifting or alternating sinusoidal gratings and moving random dots, with variation of many stimulus parameters, to provide direct comparison with neuron responses in the thalamocortical visual system. We found the principal response properties of SGS1 neurons to be very different from those described in the literature for SGS. First, the description of receptive field (RF) structure as constituting a center from which ON-OFF responses can be elicited and a silent antagonistic surround from which no responses can be evoked was not confirmed. Second, the same neurons that responded strongly to flashing stimuli unexpectedly showed robust orientation tuning to moving or alternating gratings. Third, in many neurons responses to a drifting grating patch presented at the RF center showed strong orientation-specific modulation by an annulus grating in the RF surround. The SGS1 neurons also showed diverse response dynamics to the presentation of periodic stimuli.

\section{METHODS}

\section{Animal preparation}

Long-Evans hooded rats $(n=17)$ were used in this study. They were bred in the University of Utah animal facility from stock purchased from Charles River Laboratories. All procedures used on animals were reviewed and approved by the University Animal Care and Use Committee and were consistent with National Institutes of Health and Society for Neurosciences guidelines.

Animals were anesthetized with an intraperitoneal injection of ketamine $(100 \mathrm{mg} / \mathrm{kg})$ and xylazine $(10 \mathrm{mg} / \mathrm{kg})$. Fur was removed from the dorsal surface of the head while the skin was kept intact. The animal was placed in a stereotaxic apparatus. An effective anesthetic state was ensured throughout the experiment by monitoring the heart rate and muscular activity with an amplifier connected to the animal hind leg by a wire loop. Increase in heart rate and appearance of electrical signs of muscle activity signaled the need for anesthetic supplementation. A thermostatically controlled heating blanket was used to maintain the body temperature at $37^{\circ} \mathrm{C}$. Lidocaine was topically applied to the eye contralateral to the SC being studied and a neutral contact lens was put on the eye. The edge of the lens received enough support from the eyelids to avoid significant eye movements that might interfere with the experiment, as could be judged by RF stability in the course of response recordings (see following text). The cornea of the opposite eye was covered with protective eye ointment to prevent it from drying.

A metal guide tube $(0.5 \mathrm{~mm}$ in diameter, $0.5 \mathrm{~mm}$ long) was pressed, together with an intact skin patch under the tube, to the skull over the region of the SC receiving input from the frontal visual field (over an area with coordinates around $3.5 \mathrm{~mm}$ rostral and $0.5-1.5 \mathrm{~mm}$ lateral relative to the interaural and midline planes, respectively). This region represents the visual field from the vertical meridian (VM) to $40^{\circ}$ lateral, and from -10 to $30^{\circ}$ relative to the horizontal plane. A majority of recorded neurons had their RFs close to VM and 10-20 above the horizontal plane. A small opening $(0.2 \mathrm{~mm}$ in diameter) was drilled by the guide tube through the skin and skull. A glass cannula of a diameter close to that of the skull opening was inserted into it without penetrating the dura mater membrane. A microelectrode was introduced into the brain through the cannula. This procedure is as minimally invasive as possible and allows maintenance of sterile conditions throughout as well as very stable recordings. At the end of the experiment, the cannula was removed and the skin lesion was treated with antibiotic ointment. Because of the microscopic size of the damage area, no sutures were needed. The animal was allowed to recover from the anesthesia, returned to its home cage, and rested before being used for further recording sessions (up to five separated by 3-4 days). In six animals the primary visual cortex (V1) was ablated to study the effects of decortication on the response properties of SGS1 neurons, both acutely and chronically. In these experiments, a craniotomy $2.5 \mathrm{~mm}$ in diameter was made over V1 (center coordinates: $1 \mathrm{~mm}$ anterior to lambda, $3.5 \mathrm{~mm}$ lateral) before starting SC recordings. After insertion of the microelectrode into SGS1 and characterization of neuron responses in an intact state, we aspirated a portion of the visual cortex approximately $4.5 \mathrm{~mm}$ in diameter through the craniotomy to the depth of the white matter (using a tangential approach with a suction pipette to make a lesion diameter more than that of a craniotomy). The most mediofrontal part of the SC is not overlapped by V1, which allows making recordings in the SC during VI ablation. Usually the most caudal part of the V1, underlying the sinus and representing the inferolateral extreme of the visual field, was left intact. Leaving this area unablated was considered unimportant because the RFs of SC neurons under study were located close to the VM above the horizontal plane. The location and extent of the cortical ablation ensured the removal of cortical projections to the area of SC from which recordings were performed. During cortical ablation, multiunit neuronal activity in SGS1 to flashing light spots was monitored. Single-unit recordings in SGS1 were continued after completion of the cortical ablation. At the end of the recording session, the skull opening was closed with a plastic lid, the skin was sutured, the animal received an intraperitoneal antibiotic injection (gentamycin, $0.05 \mathrm{ml} / 100 \mathrm{~g}$ body weight), and was allowed to recover as usual. Further recordings were performed $\leq 2$ wk postlesion to study the chronic effects of the ablation. Subsequent to the final recording session, the brains were fixed and the extent of the lesion was confirmed histologically; in each case it extended to the white matter.

\section{Recording site and microelectrodes}

We made tungsten-in-glass microelectrodes with tiny tips approximately $1 \mu \mathrm{m}$ in diameter and $1-2 \mu \mathrm{m}$ in length (Fig. $1 B$ ). In a vertical penetration, the SC surface was localized with the microelectrode advancing through the overlying cortex and hippocampus in the following manner. As the electrode approached the SC, complex spikes of high amplitude characteristic of hippocampus activity were followed by complete silence over the next $100-250 \mu \mathrm{m}$ as the microelectrode passed through the ventricle. As the microelectrode was advanced further, we encountered low-amplitude noise, generated in the SGS1 in response to visual stimulation. At this point, a flickering spot of light was placed in the RF location corresponding to the region of strongest response. Immediately after penetration of the pia over the SC (which again was clearly heard), the microelectrode entered the SGS1. The main body of our data presented here is based on recordings made from the neurons encountered within the SGS1 layer, the upper $100 \mu \mathrm{m}$ after SC surface penetration. The SGS1 was identified, in the presence of visual stimulation, by a very characteristic noise produced by "juxtazonal potentials," first described in experiments conducted on cats by McIlwain (1978). This noise reflects massive unitary extracellular potentials unique to this sublamina and is a result of retinal axon spikes invading their terminal arbors in the SGS1. The noise diminished sharply as the microelectrode left the SGS1 at a depth of 100-150 $\mu \mathrm{m}$ from the SC surface. Usually only one or two cells could be isolated within the SGS1 in one 
A

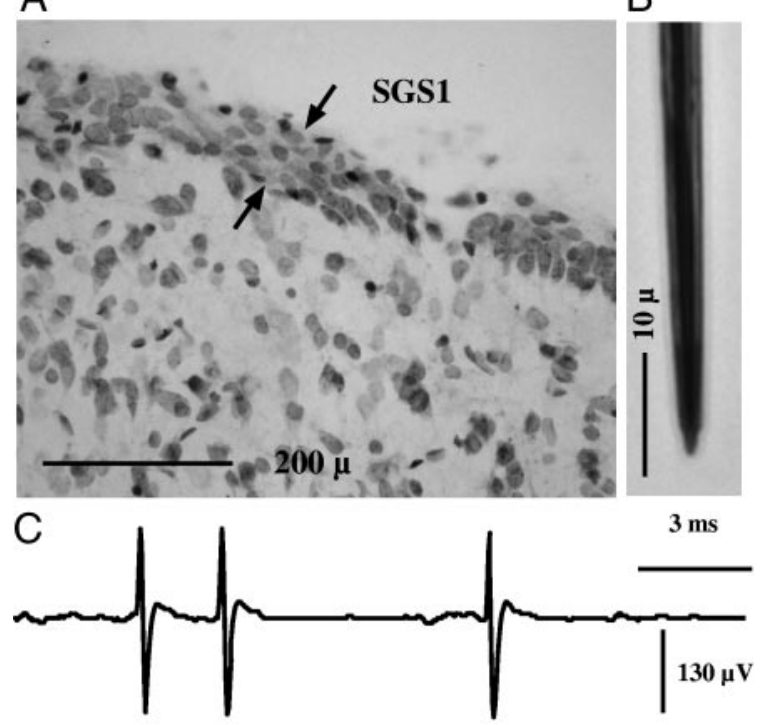

FIG. 1. A: frontal section through rat superior colliculus (SC) showing the uppermost sublamina of stratum griseum superficiale (SGS1; cresyl violet staining). $B$ : high-power magnification view of a microelectrode showing its uninsulated tip. $C$ : typical example of spikes recorded from SGS1 neurons.

vertical penetration. To isolate more cells, we raised the microelectrode by $1.5-2 \mathrm{~mm}$ and made a small horizontal displacement of the electrode holder with a micromanipulator, slightly bending the microelectrode. Lowering it again allowed us to isolate neighboring cells in the SGS1. Because the cells within this layer had no or very low spontaneous activity, the microelectrode unit isolation was performed while the stimuli effective in eliciting responses were presented on a monitor. Isolation of single-neuron discharges in this layer was a challenging task and could be achieved only with our very thin and sharp microelectrodes. They imposed minimal pressure as they penetrated the pia and advanced through the neural tissue and were very effective in resolving spikes of individual cells within this layer of tightly packed small cells (somata around $10 \mu \mathrm{m}$ in diameter, Fig. 1). Larger electrodes failed to isolate single-unit responses in this sublamina. In all our recordings, single units were clearly isolated from their neighbors and, as judged by spike shapes, amplitudes and stability of recordings were obtained from cell bodies rather than fibers. The typical spikes recorded in the experiments are shown in Fig. $1 C$. The deep boundary of SGS1 was determined by the loss of "juxtazonal potentials" and corresponded well with anatomical SGS1 delineation (Langer and Lund 1974). We were unable to exactly mark the positions of recorded cells: because of the very small uninsulated microelectrode tip, the current needed to create an electrolytic lesion destroyed the microelectrode before producing any recoverable mark. Instead, in separate experiments, we used larger microelectrodes with tips of 5-8 $\mu \mathrm{m}$, which still were able to identify the SGS1 layer by "juxtazonal potentials" and locate the SGS1 lower border, where a lesion was made. We confirmed that the physiological characteristics detailed earlier, and micromanipulator readings, were sufficient to ensure that our recordings were made within $100 \mu \mathrm{m}$ from the SC surface.

In some penetrations we continued the search and characterization of single-unit responses, advancing the microelectrode $200-300 \mu \mathrm{m}$ deeper after leaving SGS1 to compare response properties of neurons in SGS1 and those in the deeper part of the SGS (down to the stratum opticum).

\section{Visual stimulation, data acquisition, and analysis}

Visual stimuli were created with Neurophysiology software (Vision Research Graphics, Durham, NH). Stimuli were presented in black and white mode on an NEC FE 950 monitor (screen size $360 \times 270$ $\mathrm{mm}$, frame rate $120 \mathrm{~Hz}$, resolution $800 \times 600$ pixels) positioned 45 $\mathrm{cm}$ from the animal's eye (the screen occupied $46 \times 34^{\circ}$ in the visual field). The background screen illumination was $30 \mathrm{~cd} / \mathrm{m}^{2}$ indicated as "Gray" in RESULTS. Spatial and temporal patterns of flashing stimuli are presented in Fig. 2D. A stimulus set included presentation of 1) alternating "Black" and "White" (2 and $58 \mathrm{~cd} / \mathrm{m}^{2}$, respectively) circles or annuli on a "Gray" background; 2) alternating uniform whole screen "Black" and "White," interleaved by "Gray" brightness; 3) the same as 2) but having a central disk ("hole") of constant "Gray" illumination (in some tests the "hole" and background brightness were both set to "Black" or "White"); 4) drifting or alternating sinusoidal grating patches or grating annuli with varying spatial and temporal frequencies and orientations; and 5) light shapes (circles) or coherent random dots (light squares of $1.75 \times 1.75^{\circ}$, in sufficient number to cover $50 \%$ of the stimulus area) moving with varying directions and velocities. The mean luminance of the gratings and random dot stimuli was adjusted to $30 \mathrm{~cd} / \mathrm{m}^{2}$, the same as a screen background, assessed using a Minolta L-100 luminance meter. Grating contrast was measured as approximately $75 \%$.

Neuronal activity was amplified, filtered (200- to 3,000-Hz bandwidth), and played over a loudspeaker. Neuronal spikes transformed into standard impulses by an amplitude window discriminator were passed, together with stimulus triggers from the running stimulus presentation software, to a CED 1401 data acquisition system under control of Spike2 software. The Spike2 script language program performed on-line data processing: it calculated peristimulus time histograms (PSTHs) for each separate stimulus presentation, averaged them and calculated the SE values, calculated fast Fourier transformation of histograms for grating stimuli to obtain F0 and F1 response components, produced the charts presenting them as functions of varying stimulus parameters, and stored the raw data for off-line analysis.

Once single-unit spikes were isolated, we checked the position of the RF with a flickering spot or drifting grating patch. As a result of the brisk responses to this stimuli and the virtual absence of spontaneous activity, it was easy to precisely locate the RF center. Then the screen center was adjusted to the RF position. The stimulus was centered on the screen and its position was locked with the software option. The RF position generally showed high stability (see Fig. 6 for an illustration), but at any sign of RF displacement we remapped its position as described earlier.

For quantitative analysis of neuronal responses to grating stimuli, gratings were presented in several blocks of trials in which the stimuli with particular parameter values, as well as blank trials to assess the neuron's spontaneous firing rate, were presented in random order. Trial duration was set to a fixed number of grating cycles, usually ten, and thus was dependent on the grating temporal frequency (TF, typical value $5-8 \mathrm{~Hz}$ ). Results of several repeated blocks (not fewer than three and usually four to six) were averaged. To reveal the dynamics of SGS1 neuron responses to gratings, we also averaged, over repetitive trials, the responses separately for each consecutive grating cycle and fitted them into three-dimensional (3D) response versus varying stimulus parameter charts where the third dimension was time in terms of the grating cycle number (a real-time scale is a reverse of the grating temporal frequency).

\section{RES U L T S}

We present results from single-unit extracellular recordings of 146 neurons from the SGS1 in intact animals and of 41 cells in animals with V1 ablation. Most units were held long enough to test their responses to the full stimulus set chosen for their characterization. The majority of the cells showed no or low spontaneous activity (SA). 

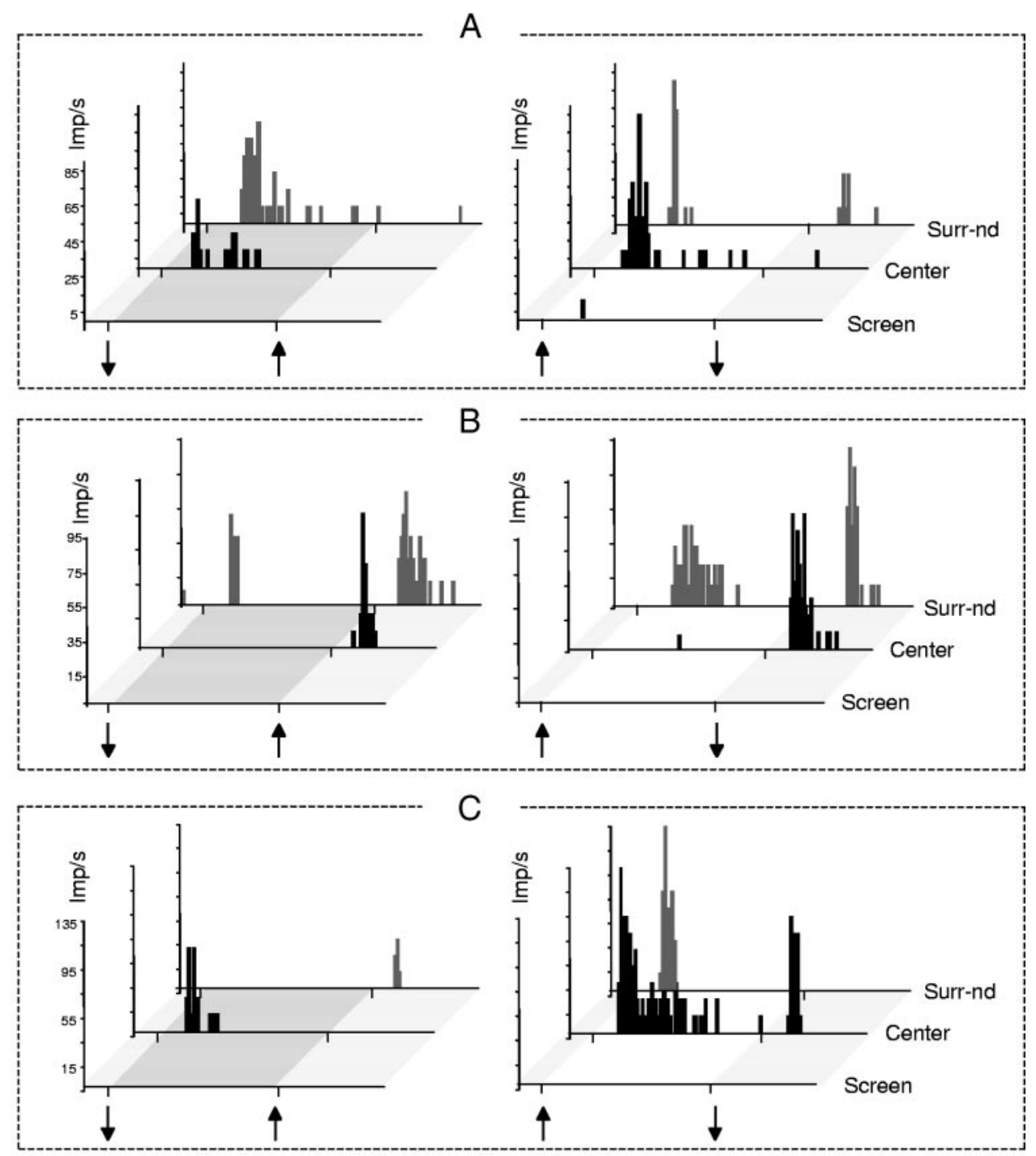

FIG. 2. $A-C$ : typical examples of peristimulus time histograms (PSTHs) recorded in 3 cells in response to different flashing stimuli. $D$ : time course of brightness alternations and the stimulus configurations used in these tests: 1) flickering uniform whole Screen; 2) flickering circle in the neuron receptive field (RF) Center; 3) flickering Surround alone, with a disk ("hole") of permanently gray (background) illumination in the RF center. Cells were absolutely silent during presentation of the whole flickering Screen; they responded to both Center and Surround flickering stimuli, and responses elicited from the center and surround were nonantagonistic. Records are made in 10-20 blocks of trials. Arrows indicate brightness transition time points and their signs; OFF, down; ON, up. PSTHs time bin: $7.0 \mathrm{~ms}$; $y$-axis scales, in spikes per second.
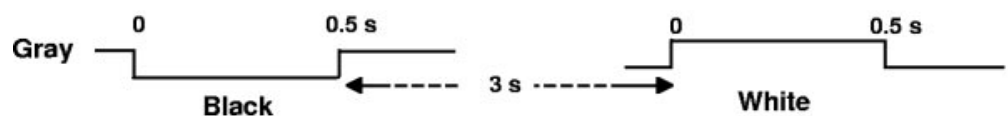

Gray
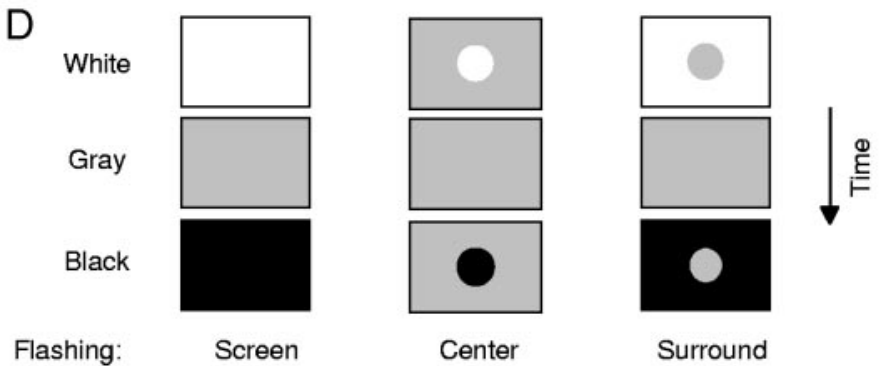

\section{Responses to flashing stimuli}

All neurons recorded within SGS1 responded to flashing light spots, mainly with high-frequency bursts of activity, as can be seen in the examples shown in Figs. 2 and 3. The RF centers of the neurons were easy to locate by presenting a flashing spot of light $2-3^{\circ}$ in diameter and recording the responses, which decreased rapidly to zero when the stimulus shifted from the optimal position. Cells responded to a broad

range of flicker frequencies $\leq 15 \mathrm{~Hz}$. We encountered no cells showing antagonistic responses when the stimulus was placed outside the central RF area. We did find that the majority of cells could not be classified unambiguously as on and/or OFF cells. When flashing Center (the stimulus configuration shown in Fig. 2D, middle) was presented, the same cell showed a response to Gray-White (on-transition) and no response to Black-Gray (also on-transition but at different illumination 

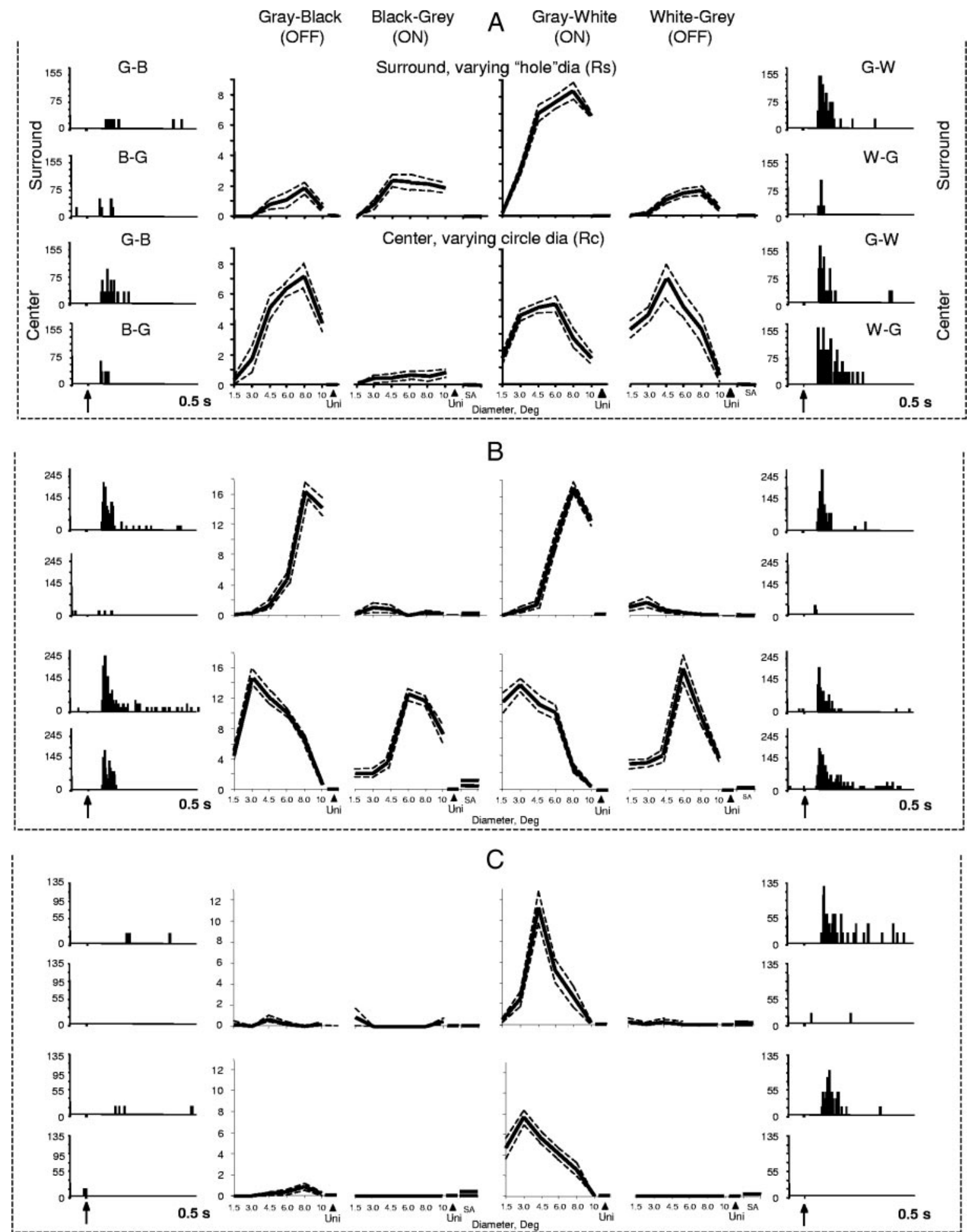

FIG. 3. A-C: examples of response vs. diameter (R vs. D) curves obtained with Center and Surround stimulus configurations, as shown in Fig. $2 D$, in 3 cells. Graphs in the middle: R vs. D curves recorded separately for 4 brightness transitions as indicated at the top. Top 2 graphs in each example are those recorded with Surround stimulus varying the "hole" diameter in the RF center; the bottom 2 graphs are those recorded varying the diameter of flashing Circle in the RF center. These experiments constitute "complementary center-surround stimulation" test (see the APPENDIX $>$ ). Note that the neurons responded to the same brightness transition(s) of the Center and Surround in the same range of the circle and "hole" diameters, which is incompatible with a summation model of the $\mathrm{RF}$, taking into account the absence of the responses to the flashing whole screen. $x$-axis shows the diameter in degrees of visual angle, "Uni”" indicates responses to uniform whole flashing screen (they are absent in each case), and SA indicates spontaneous activity during presentation of blank screen (gray level). Responses are shown as means \pm SE spike rate averaged for a period of $0.5 \mathrm{~s}$, starting at $50 \mathrm{~ms}$, the minimal latent period of response after the brightness transition. PSTHs at flanks in each example show responses to stimulus brightness transitions as indicated in $A$ (the same in $B$ and $C$ ) obtained with the diameter of the "hole" or the circle producing maximal response. Time course of brightness alternations: as indicated in Fig. $2 D ; y$-axis-in spikes/s; PSTHs time bin: 4.7 ms; arrows indicate the moment of the brightness transition. 
level), as illustrated in Fig. 2, $A$ and $C$. The same was observed with opposite transitions: it was possible to receive an ofF response to the Gray-Black transition and no response to the White-Gray transition, as shown in Fig. $2 A$, or only on response to the Gray-Black-Gray transitions, and only ofF responses to Gray-White-Gray transitions (Fig. 2B). Thus it appears that the cells responded not to the specific brightness transition signs but to the appearance or disappearance of spots that were either darker or brighter than the background, or both. When tested with flashing spots of increasing diameter, responses in the majority of cells (112/146) for any or particular transitions of stimulus brightness increased to the maximum (in a range of spot diameters $1.5-10^{\circ}$ ), thus revealing what is commonly considered as a spatial summation within the RF center; responses decreased thereafter. Examples are presented in Fig. 3, A-C, Center stimulus (which also provides additional illustration of a problem with $\mathrm{ON}-\mathrm{OFF}$ response classification). Fewer cells showed a monotonic response increase with the spot diameter. These profiles of response versus diameter ( $\mathrm{R}$ vs. $\mathrm{D}$ ) curves are typical of those recorded throughout the visual system at various levels. Flashing GrayWhite-Gray-Black-Gray presented uniformly over the whole display Screen (the stimulus configuration shown in Fig. 2D, left) rarely produced responses (in only 11 of 146 cells tested) and when present they were very weak (see Fig. 2, $A-C$, histograms obtained with Screen stimulus, and Fig. 3, "Uni" marks at the $x$-axis).

Surprisingly enough, but in accord with our interpretation regarding ON-OFF responses (see above), the cells showed vigorous responses when tested with the Surround stimulus (configuration shown in Fig. 2D, right) composed of a circle of permanently Gray brightness (which forms a "hole" where brightness changes are absent) centered on the RF and surrounded by a flashing remainder of the screen. To an observer, the center appears to be flashing and the cells responded similarly. Examples of responses are shown in Fig. 2, $A-C$, Surround stimulus. To make absolutely sure there were no residual illumination changes in the RF center that could produce these responses, we masked the entire screen except for the gray "hole" and recorded responses during stimulus presentation. These were consistently absent. Responses to the Surround stimulus were present irrespective of the luminance level of the central "hole": gray, black, or white, as long as they contrasted with the brightness of the "hole." More surprisingly, taking into account an absence of responses to the whole flashing Screen, the responses were elicited by the same brightness transition(s) of the flashing periphery presenting Surround stimulus and of the flashing center presenting Center stimulus, as can be seen in Fig. 2, so these responses were not antagonistic. This was in contrast to what can be expected if neurons had an antagonistic center-surround organization: neurons showed no responses to uniform flashing Screen and they had to be even more inhibited with Surround stimulus when the center stimulation was reduced. However, perhaps some possibility remained that these seemingly unusual responses still were the result of center-surround interplay and, with other diameters of the central flashing spot or of the "hole" in Surround stimulus, the responses could reveal normal center-surround pattern of RF. To check that, we applied the "complementary center-surround stimulation" test described in the APPENDIX. The typical results of the tests with three cells are presented in Fig. 3 where the curves of R versus D obtained with varying diameter of the Center stimulus were compared with those obtained with varying diameter of the "hole" in Surround stimulus; the diameters were varied in the same range. These experiments demonstrated that when Surround stimulus was presented with varying the "hole" diameter, the response with respect to the diameter of the nonstimulated central area showed qualitatively similar profiles, of comparable magnitude (for some or any brightness transitions) and nonantagonistic to those recorded with the flashing central spot of varying diameter in the whole range of diameters (Fig. 3, $A-C$ ), whereas, according to a summation model, the responses to the Surround stimulus have to be absent. Thus neither "spatial summation" nor "interplay between RF center and surround" suggests an appropriate explanation of the R versus D profiles obtained with Center or Surround stimuli. Additional justification is provided in the DISCUSSION section and in the APPENDIX, although this is obvious in the case of Surround stimulus: using this stimulus configuration, the RF central area where a blank "hole" projects is not being stimulated at all; thus a summation mechanism cannot explain the observed $\mathrm{R}$ versus D profiles.

The magnitude of response to the flashing Surround dropped sharply with an increase in eccentricity between the RF and the "hole" centers, similar to that observed with the Center stimulus.

In addition, we tested some of the cells (18/146) with flickering annuli of varying outer diameter, centered on the RF, and of constant difference between outer and inner radii ("contour" thickness), set to $6-2.5 \mathrm{~mm}\left(0.7-0.3^{\circ}\right)$ in different tests. Responses to these stimuli were compared with those recorded in the same cells to flickering circular solid spots for which diameter was varied in the same range as the outer diameter of the annulus. We found that typically the $\mathrm{R}$ versus $\mathrm{D}$ profiles recorded with annular and solid circle stimuli were similar. Response magnitudes for both stimuli were comparable when thickness of the "contour" was $\gtrsim 0.5^{\circ}$; as the "contour" was thinned further, response dropped sharply (Fig. 4).

When tested with moving light spots, all SGS1 neurons responded with brisk activation in a wide range of movement velocities, usually preferring high speeds of movement $\left(>30^{\circ}\right.$ ) s), but they showed no or weak tuning for direction of movement (see Neuron response properties recorded in the SGS deep to the SGS1 layer). Thus it seemed that simply the appearance and disappearance of the light spot in the RF rather than movement itself produced these responses.

\section{Responses to moving gratings}

Most neurons (122/146) responsive to uniform flashing stimuli also showed strong responses to moving gratings and some of them also responded to stationary alternating gratings. F0 and F1 components of the responses typically were quite similar, so only the F0 component is shown in Figs. 5-9. Responses to consecutive grating cycles usually showed substantial changes during the course of stimulus presentation. These changes could be seen as a decline in response amplitude, well known as a response accommodation or habituation in the SC, although responses could also escalate and, in some instances, fluctuate, as shown in the 3D charts in Figs. 5-9. The figures show the responses averaged separately for each con- 

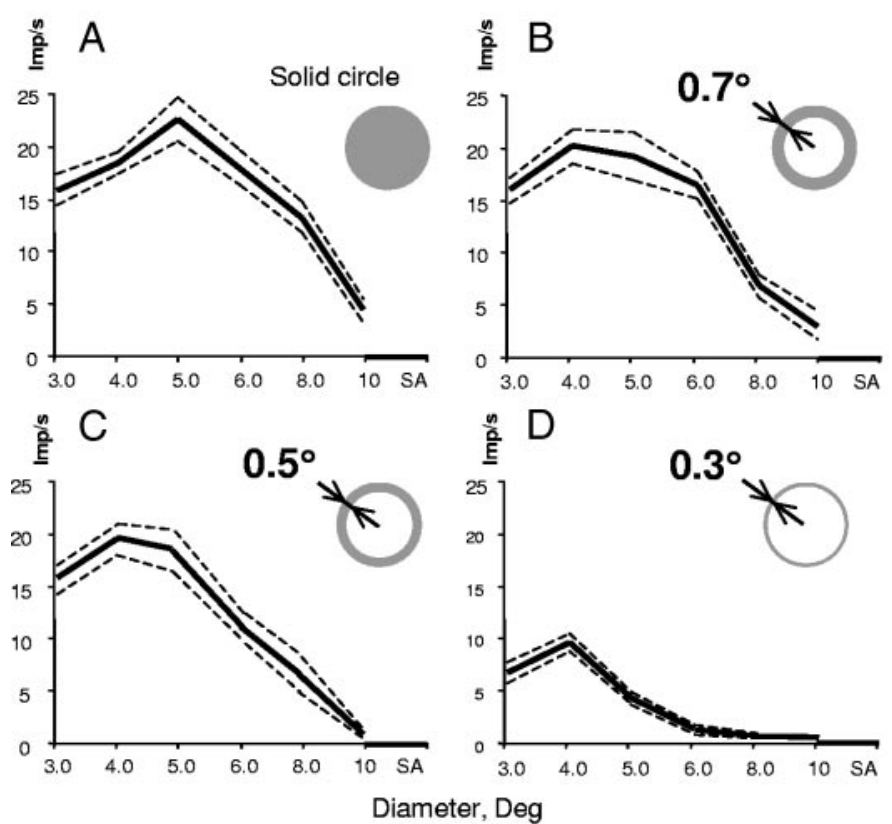

FIG. 4. An example of R vs. D curves recorded with different flashing stimuli (shown beside the graphs) varying the diameter of the circle or annulus. All records were made from the same single cell, for White-Gray brightness transition, which produced maximal response with each stimulus configuration.

secutive grating cycle (3D charts) in the course of several trials (not fewer than three and usually four to six), as well as responses averaged for all grating cycles together (2D charts; solid lines: mean value, dashed lines: $\pm \mathrm{SE}$ ).

ORIENTATION SPECIFICITY OF RESPONSES. This is illustrated in Fig. 5. Clear orientation response (OR) tuning to gratings was found in 103 of the 122 cells responsive to grating stimuli. Some cells (58/103) were quite sharply tuned, with $<60^{\circ}$ half band-width at half response peak-dip difference; in 24 cells this value was $<80^{\circ}$, whereas the rest showed weaker orientation tuning. Orientation responses, similar to responses with other varying stimulus parameters, showed significant and diverse dynamic changes in the course of grating presentations, as illustrated in Fig. 5. Response habituation (Fig. 5, $A$ and $B$ ) was more commonly seen than response escalation (Fig. $5 C$ ) or response fluctuation (Fig. $5 D)$. When a cell showed dynamic response changes, OR tuning usually was sharpened gradually with consecutive grating cycles; responses to the first grating cycle might show a total absence of OR tuning (Fig. 5C) or very poor tuning, but in the course of several iterations the OR tuning developed and sharpened.

Those OR-tuned cells that were responsive to both drifting and stationary alternating gratings showed the same or closely similar OR tuning with both types of gratings, although their response amplitudes and dynamics might differ.

Some OR-tuned cells also showed tuning to grating drift direction, as assessed by significant peak response asymmetry to optimally oriented gratings moving in opposite directions; however, direction selectivity, using a criterion of $\geq 50 \%$ difference between the responses to grating of optimal orientation and of orientation, differed by $180^{\circ}$ (drifting in opposite direction) and was encountered in only 18 of the 103 OR-tuned cells recorded (an example is shown in Fig. 5A).
CENTER-SURROUND INTERACTIONS. In those OR-tuned cells showing a decreased response when the diameter of the grating patch exceeded the optimum size (these cells constitute a majority of those recorded; see following text), we studied the effects of a grating annulus presented in RF surround on responses elicited from the RF center by the grating patch whose diameter and orientation were set to optimal. The inner annulus diameter was equal to the diameter of the central grating patch and the outer diameter was $15-20^{\circ}$. When a cell showed a sufficiently strong response to the central patch grating, both optimal and orthogonal to optimal orientations, the center-surround interaction tests were performed with these two orientations of the central patch. The orientation of the annulus grating was varied, whereas the spatial and temporal frequencies (SFs and TFs, respectively) of both central and peripheral gratings were the same. Annulus gratings, which were able only to elicit responses much weaker than optimal ones produced by central patches, or elicited no responses at all, always strongly modulated the response to the center patch in an orientation-specific manner. Examples are shown in Fig. 6. When the orientations of the central patch and annulus gratings were orthogonal, there was weak or no inhibitory effect of peripheral (annulus) stimulation on the central response and response facilitation was sometimes observed. The annulus grating imposed the strongest suppressive effect on the central response when both gratings were collinear. Effects of the annulus gratings drifting in opposite directions (in graphs their orientations differ by $180^{\circ}$ ) were always the same by sign despite the fact that in some cells, they differed in amplitude. In cases in which the orientation of the central patch was rotated by $90^{\circ}$ and the test was repeated (Fig. 6, $A-C$, right charts), the orientation modulation profile also shifted by $90^{\circ}$, invariant to the orientation of the central patch: maximal and minimal responses were observed to correspond with annulus gratings orthogonal to and collinear with the central patch, respectively.

In cases in which the cells showed responses to moving random dots, we varied the direction of movement of the dots presented in the RF surround and tested whether this would affect the responses to a drifting central grating presented in the center of the RF. Although moving random dots in the RF surround sometimes affected the center response, the response modulation did not occur as a function of the dots' movement direction. An example is shown in Fig. 6D, right.

As illustrated in Fig. 6A, orientation specificity of centersurround interactions usually appeared only after the first one to two cycles of the grating presentation (with typical TF values around $5-10 \mathrm{~Hz}$, this is equivalent to $100-400 \mathrm{~ms}$ ). Responses to the first cycles were typically much less orientation-specific.

RESPONSE VERSUS DIAMETER (R VS. D) CURVES. These were tested with a central grating patch and typically showed the profiles with a maximal response for a specific diameter (in a range of $3.0-10^{\circ} ; 6.3 \pm 2.4^{\circ}$, average $\pm \mathrm{SE}$ ), close to those recorded with flickering stimuli. Examples of $\mathrm{R}$ versus $\mathrm{D}$ records, as well as response dynamics recorded with two cells, are presented in Fig. 7, $A$ and $B$.

With grating stimuli, we also performed a "complementary center-surround stimulation" test (see the APPENDIX) similar to that applied using flashing stimuli. Our goal was to analyze 


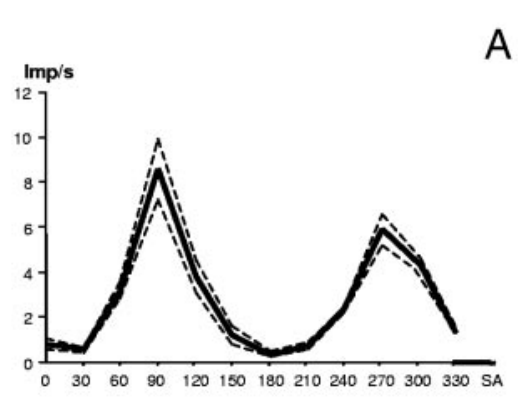

A

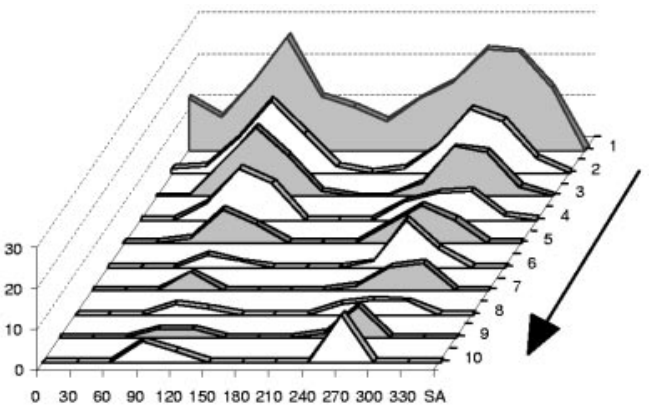

B
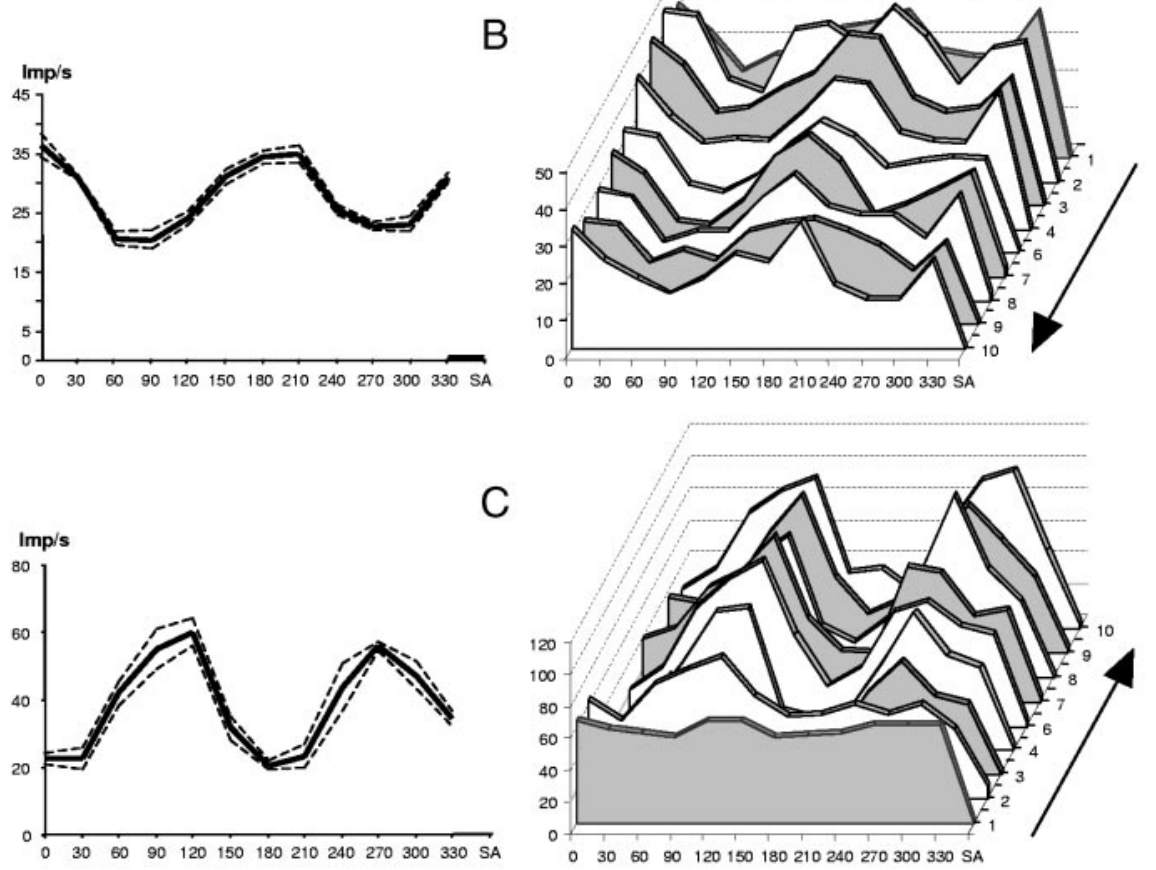

C

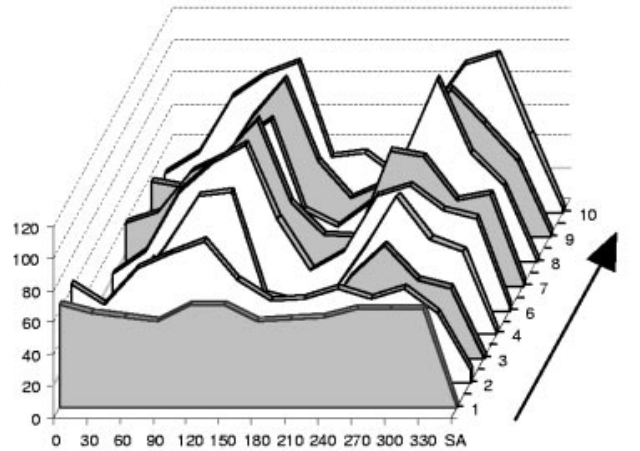

D

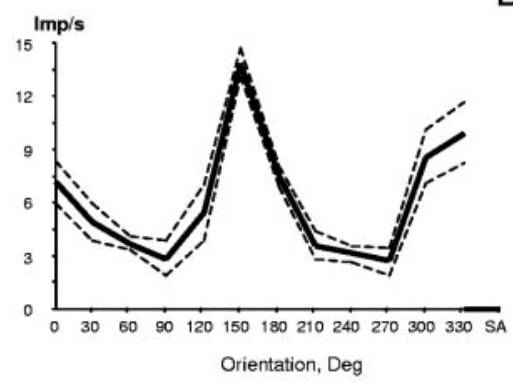

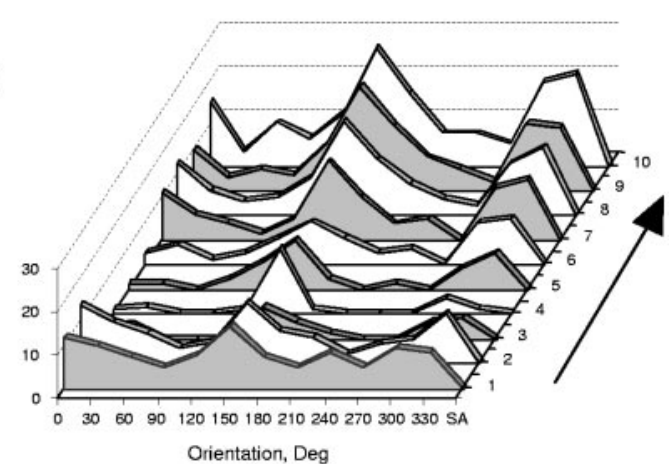

FIG. 5. Examples of response vs. grating orientation curves recorded with 4 cells. In this and subsequent figures, the 2-dimensional (2D) chart shows responses as a function of varying parameters of the grating stimulus (solid line, F0 component; dashed lines, $\pm \mathrm{SE}$ ) averaged for the whole period of grating presentation in several blocks of trials, in which varying grating parameter is assigned in a random order. Time interval between trials: $3 \mathrm{~s}$. Three-dimensional (3D) chart shows the same average responses as in the chart beside it, but an average is calculated for each particular grating cycle of 10 constituting the whole period of stimulus presentation (cycle number is indicated at the time axis). Arrows indicate the time axis direction. Time gap between subsequent grating cycles is $1 /$ temporal frequency (TF). Spatial frequency $(\mathrm{SF})=0.15 \mathrm{c} / \mathrm{deg}$; in $A$ and $D, \mathrm{TF}=6$ $\mathrm{Hz}$; in $B$ and $C, \mathrm{TF}=8 \mathrm{~Hz} . x$-axis, grating orientation, in degrees; SA, spontaneous activity. whether the $\mathrm{R}$ versus $\mathrm{D}$ curves were shaped by interplay of the RF center and surround. Typical examples are presented in Fig. $7, C-F$, and explanation of the procedures is given in the figure legend. We concluded that in the case of grating stimuli a summation model of the RF cannot explain the curves (see DISCUSSION), similar to what we found with flashing stimuli.

RESPONSES VERSUS SPATIAL AND TEMPORAL FREQUENCY OF THE GRATING PATCH. Recorded neurons usually showed tuning to low SF. Examples of responses as a function of SF are presented in Fig. 8, $A$ and $B$. The majority of neurons responded only to gratings with $\mathrm{SF} \leq 0.3 \mathrm{c} / \mathrm{deg}$. That is far below the spatial resolution limit of $1.2 \mathrm{c} / \mathrm{deg}$ recorded in neurons of the rat visual cortex (Girman et al. 1999) and in behavioral tests (Prusky et al. 2000), although it is comparable to the SF resolution figure previously recorded behaviorally after occipital decortication (Dean 1981). Interestingly, some spontaneously active cells showed inhibition of spiking in response to high SF stimuli (Fig. 8A). Some cells showed responses in the whole SF resolution range $(\leq 1.2 \mathrm{c} / \mathrm{deg})$, but only for the first one to two grating cycles. Subsequently, responses to high SFs were lost (Fig. 8B). It seems that cells actively filtered out the high SFs even though they appeared to receive input containing 

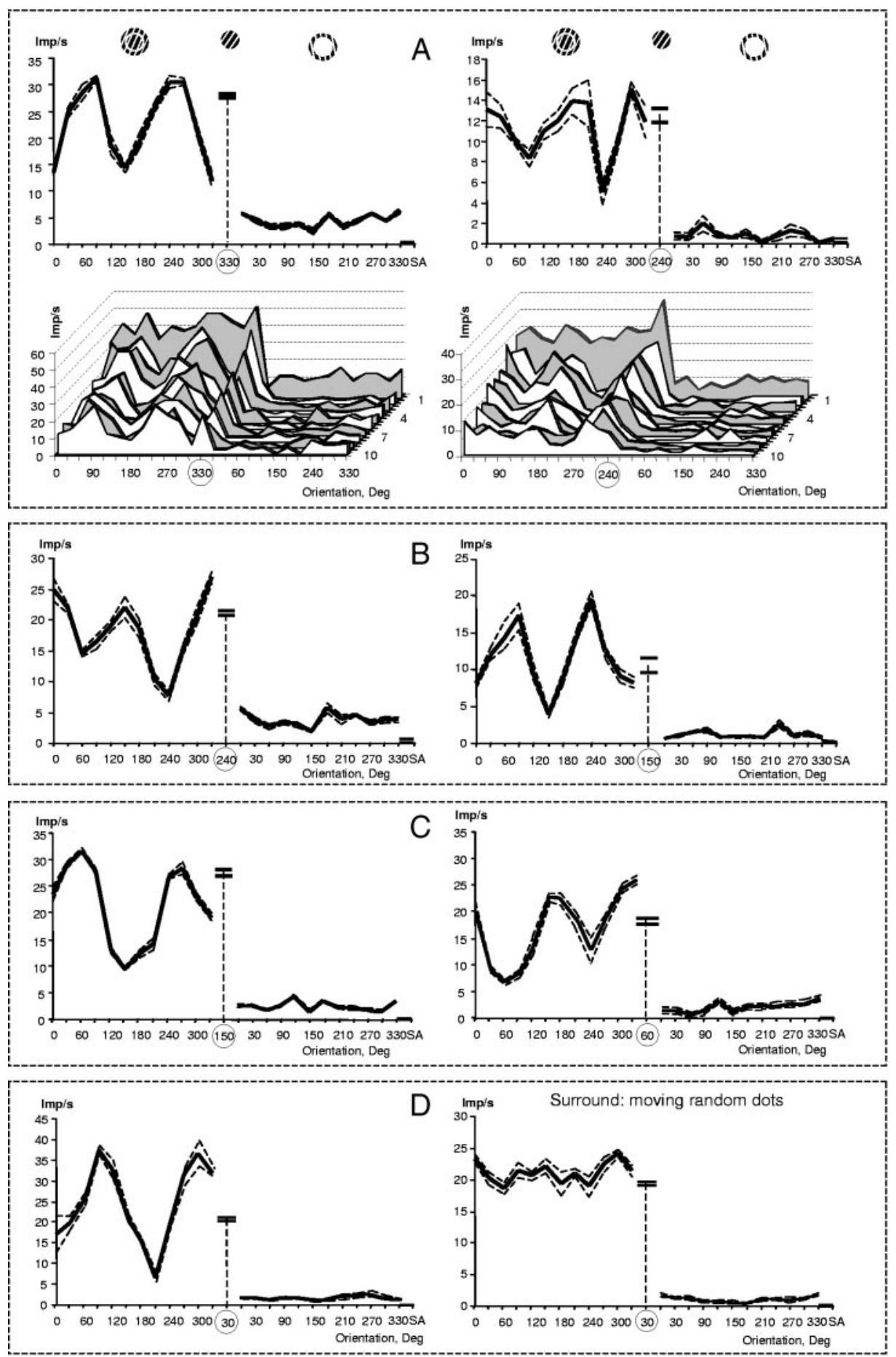

FIG. 6. A-C: examples of modulation of response to central grating patch by surrounding annulus grating, recorded with 3 cells. Response to the center grating patch alone is shown in the center of each graph (its orientation is indicated in the circle at $x$-axis). To right, responses to annulus grating of varying orientation alone are shown. To left are responses to both gratings presented simultaneously; orientation of annulus grating is varied; central patch has the constant orientation. In each example, the graphs in right and left columns were recorded with the same stimuli except that the orientations of the central grating patch in left and right columns were orthogonal. Note that although the annulus grating alone elicits weak or no response, it imposes strong orientation-specific modulation of the response to central grating, and rotation of the central grating by $90^{\circ}$ results in a shift of the modulation profile by $90^{\circ} . \mathrm{D}$ : another cell; the right chart shows responses recorded with the stimulus configurations shown in $A-C$. In the left chart, the moving random dots were presented in the surround instead of the annulus grating and their direction of movement was varied. Note strong orientation-specific center response modulation by annulus grating $(D$, left) and an absence of direction-specific modulation by moving random dots $(D$, right $) . \mathrm{SF}=0.15 \mathrm{c} / \mathrm{deg}$ in each example; $\mathrm{TF}=6.0 \mathrm{~Hz}$ in $A, 7.5 \mathrm{~Hz}$ in $B-D$, velocity of random dots $50 \%$ s. Recordings presented in these graphs were obtained in the most durable experiments. It takes $\leq 10 \mathrm{~min}$ to collect the data presented in each chart. Note the low variability of responses to the central grating, to the peripheral one, and to both of them, showing that the eye position was stable during the experiment; in fact, a correction of the RF position on the screen was unnecessary even during the whole set of experiments with each cell. this information. Some cells were optimally tuned to a specific $\mathrm{SF}$, as shown in Fig. 8B, but most behaved as low band-pass filters.

As a group, SGS1 cells showed responses to a broad range of TFs, $\leq 15 \mathrm{~Hz}$, approximately the same range as responses to flickering uniform stimuli. Many individual cells also responded to a wide range of TFs. Typical examples of response versus TF are presented in Fig. 8, $C$ and $D$.

Response versus contrast curves typically showed a gradually increased response with increasing contrast, starting in some cells from as low as $10 \%$. These responses were not studied systematically because of the difficulty of controlling stimulus contrast precisely.

\section{Effect of visual cortex ablation on response properties of SGS1 neurons}

Eighteen cells were recorded in four experiments after acute destruction of the visual cortex and 23 cells were recorded chronically in animals after cortical ablations performed 2 to 9 days before recording. Visual cortex ablation had no effect on the character of neuronal activity evoked by flashing spots and 


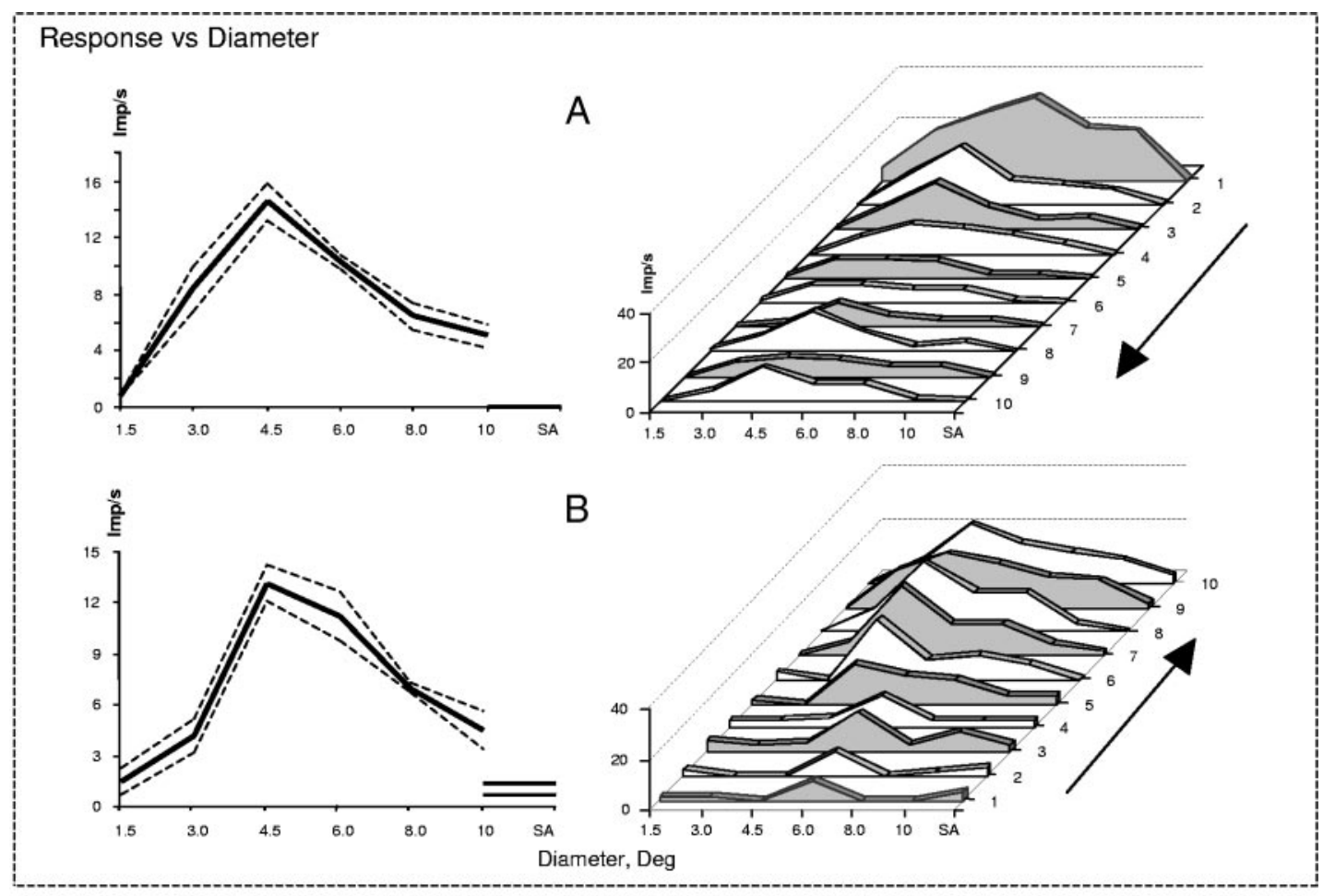

Response vs Diameter, Complementary Center-Surround stimularion test
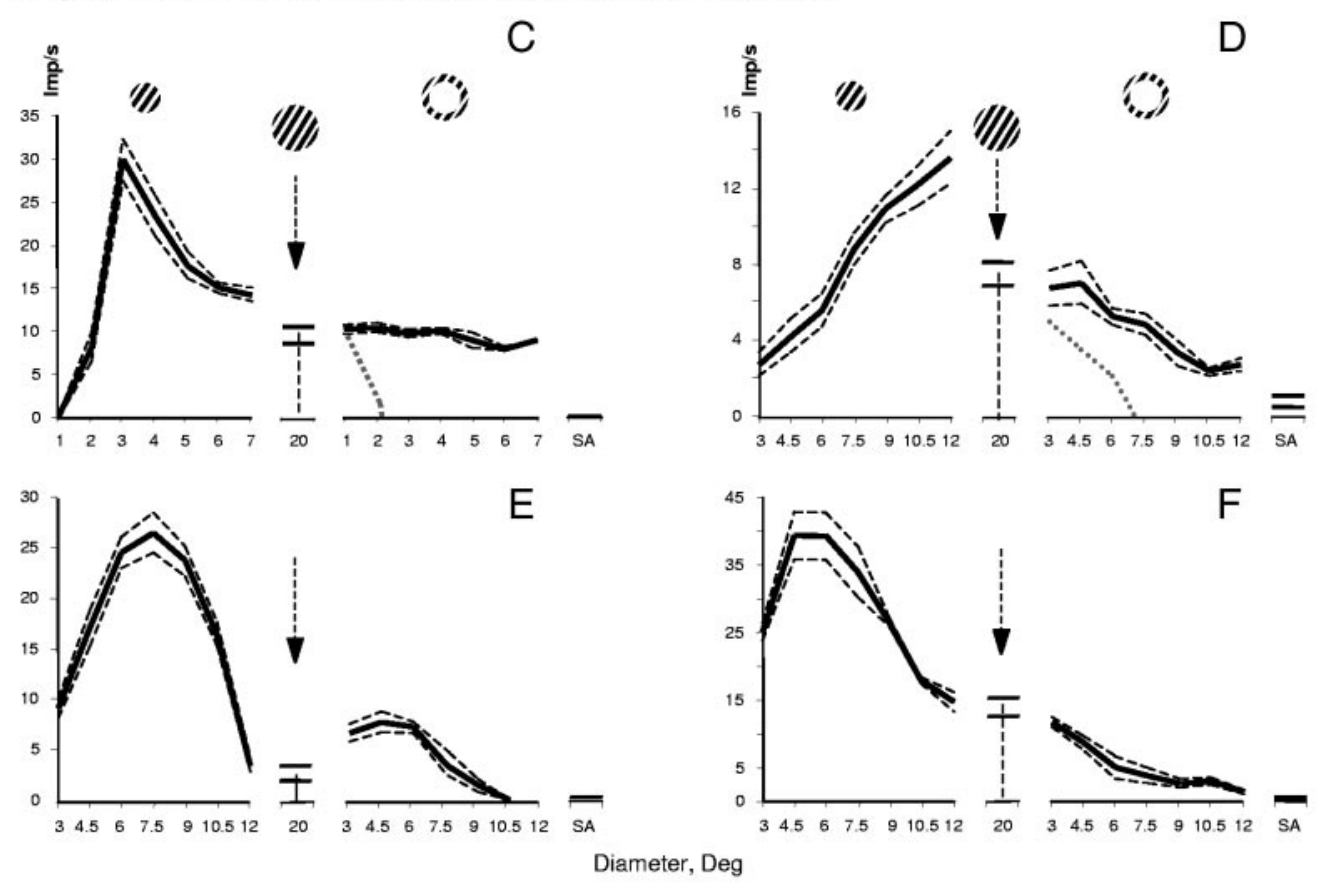

FIG. 7. $A$ and $B$, top panels: response vs. diameter curves recorded with 2 cells. Note the shift of maximal response to smaller diameters of the grating patch with consecutive grating cycles (right graphs) and different response dynamics in $A$ and $B . \mathrm{TF}=6.0 \mathrm{~Hz}, \mathrm{SF}=0.1 \mathrm{c} / \mathrm{deg}$. $C-F$, bottom panels: "complementary center-surround stimulation" test (see the APPENDIX) performed with 4 cells using drifting grating stimuli. In each graph, the curve in its left part shows the $\mathrm{R}$ vs. D of the grating patch. In the middle is shown the response to the grating patch of $20^{\circ}$ in diameter. Right curve shows the responses vs. inner diameter of the annulus grating, whereas its outer diameter was kept constant $\left(20^{\circ}\right)$; gray dotted curve below in $C$ and $D$ is a prediction of the responses to the annuli based on a summation model of neuron RF and derived from its response to the grating patches shown in the left graph's counterpart. This curve is obtained as a mirror image (relative to the half of response shown in the graph's middle) of the solid curve (average response) shown in the left graph, fitted into the right graph and truncated to its segment above the $x$-axis; gray dotted curves are absent in $E$ and $F$ because here, after applying the transformations, the curves entirely drop below the $x$-axis. Note a clear difference between the curves showing actual response to the annuli and those predicted, presented by gray dotted curves: in $C$ and $D$, the responses are much stronger than predicted and are present in the diameter range in which, assuming a summation model of RF, they have to be absent; in $E$ and $F$, responses are present in the whole range of inner annulus diameters whereas, by summation model, they have to be absent. Grating parameters other than their dimensions were set to those producing optimal responses and were the same in the 3 grating configurations. 


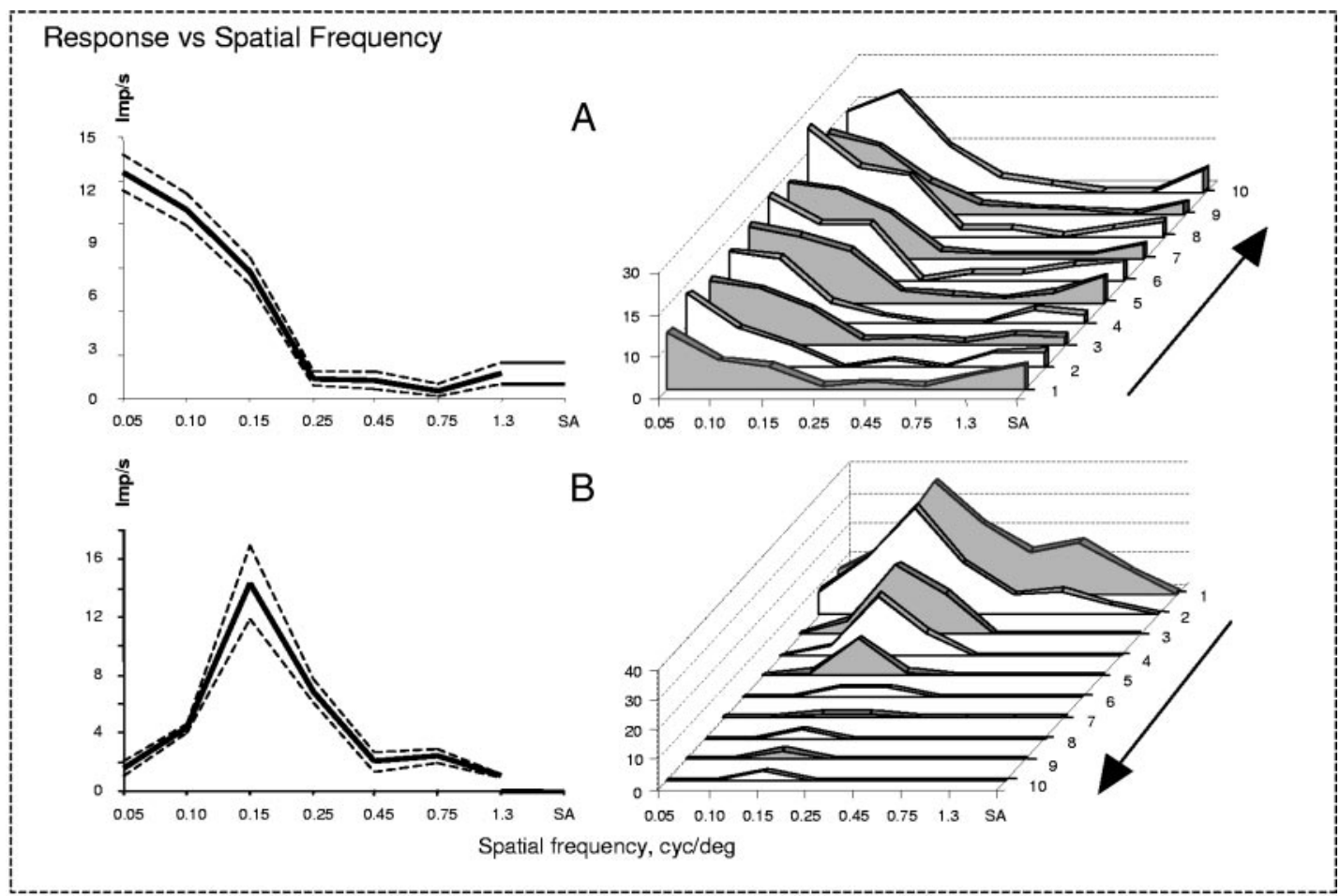

Response vs Temporal Frequency

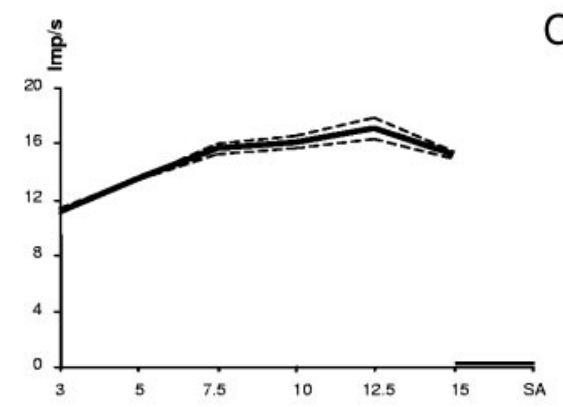

C
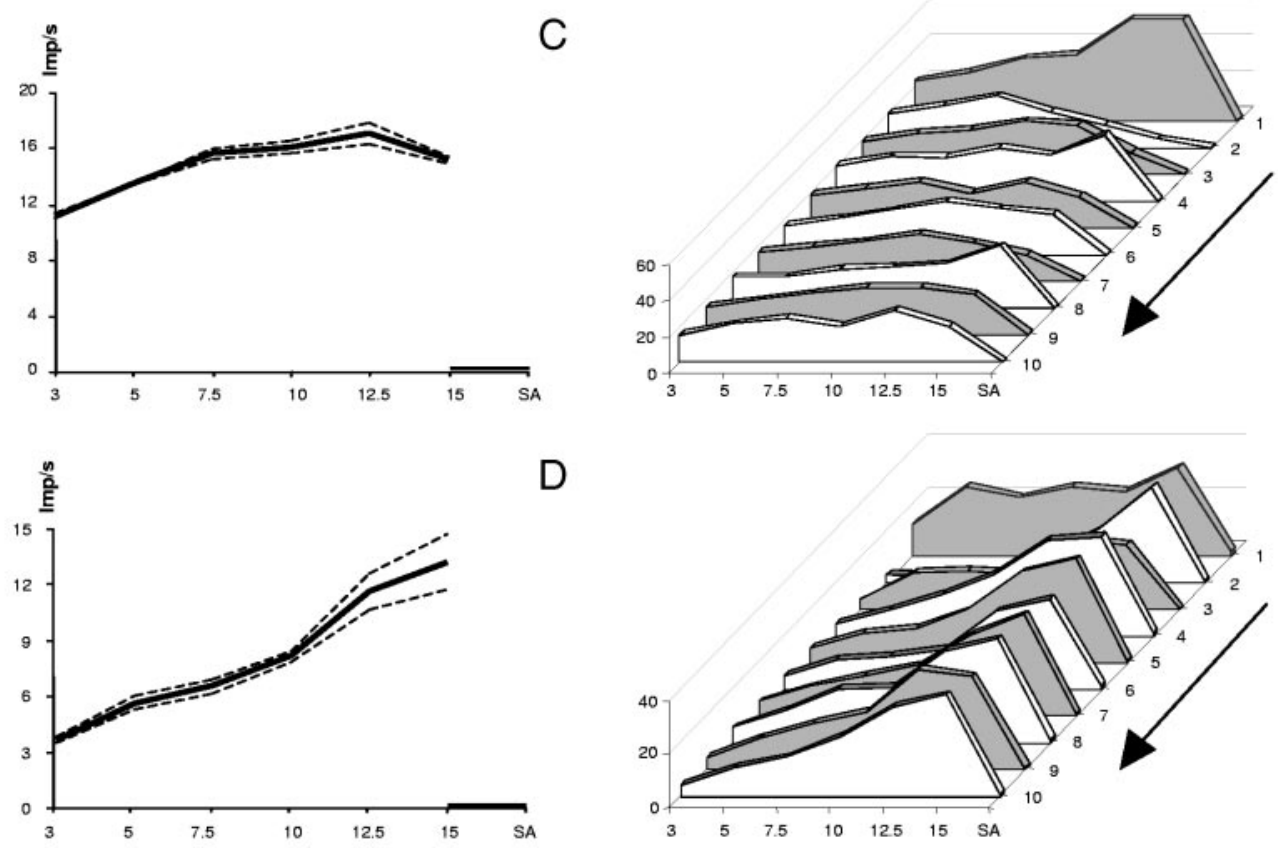

D

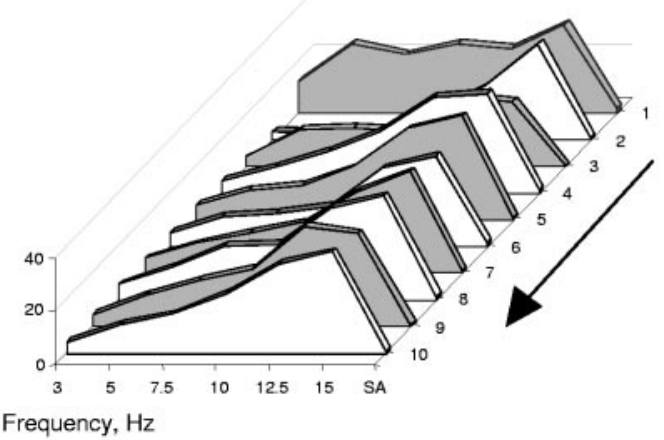

FIG. 8. $A$ and $B$, top panels: response vs. SF curves recorded with 2 other cells. Note a suppression of cell firing in the high range of SFs and a general rise of responses with consecutive grating cycles in $A$ and response habituation in $B$. TF $=5.0 \mathrm{~Hz}$ in $A, 6.5 \mathrm{~Hz}$ in $B$. $C$ and $D$, bottom panels: response vs. TF curves recorded with 2 cells. Most typical example in $C$ shows an almost absent response tuning to the movement velocity in a range from 20 to $100^{\circ} / \mathrm{s}$. Example in $D$ shows the cell preferring the velocity higher than $100 \%$ s. In both charts, $\mathrm{SF}=0.15 \mathrm{c} / \mathrm{deg}$.

drifting gratings, recorded during the course of ablation. Single cells isolated after completion of cortical ablation showed the same typical response properties as those in intact animals. These included brisk responses to flashing spots in the RF center, absence of response if the whole screen was flashing, and brisk responses to flashing periphery alone when the RF center was kept blank (Surround stimulus with a "hole"). Cells showed OR tuning and orientation-specific center-surround interactions similar to those found in intact animals. Similar results were obtained in animals with chronic cortical ablation. 

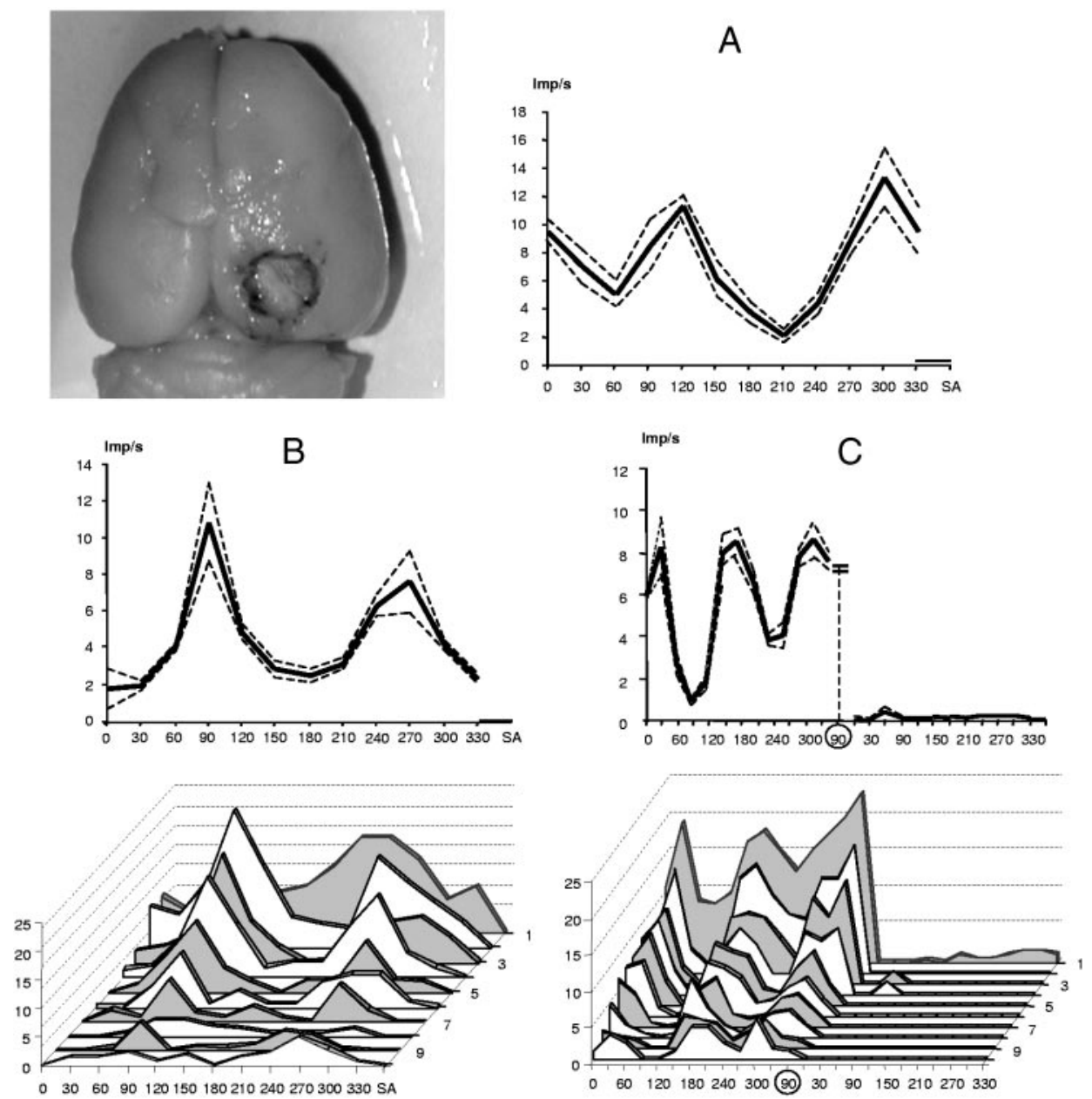

FIG. 9. Examples of responses recorded in rats after ablation of the primary visual cortex (V1). Typical extent of ablation is shown in the photograph. A and $B$ : responses to grating patch of varying orientation and an example of the response dynamics. $C$ : an example of center-surround interaction test recorded with the same cell as in $B$.

An example of cell responses recorded in animals on the second day after cortical ablation is presented in Fig. 9, $A-C$, together with a photograph of an animal's brain showing the typical extent of cortical damage.

\section{Neuron response properties recorded in the SGS deep to the SGS1 layer}

When the microelectrode left the SGS1 (as indicated by the silencing of "juxtazonal potentials" noise as described in METHoDs) and was advanced more deeply, the neurons were not as frequently encountered, in accord with the reduced cell density of SGS2 compared with that of SGS1 layer, seen morphologically, and the character of neuronal responses was noticeably changed. Neurons showed higher spontaneous activity, no or weak responses to drifting gratings, and strong responses to moving light spots with a preference for rather slow movements $(<30 \%)$. In many cases, they were tuned to direction and velocity of movement (Fig. 10A). In these respects, responses were similar to those reported previously for SGS in general. Like SGS1 neurons, however, the majority of them responded briskly and not in antagonistic mode, both to flashing light spots centered on RF and to flashing Surround with a "hole" in the RF center, whereas they had very weak or no responses to a uniform flashing screen (Fig. 10B); this property has not been previously explored. Examples illustrating the differences in responses of an SGS1 neuron and one located within SGS2 to moving stimuli are shown in Fig. 10, $C$ and $D$. The properties of SGS2 neurons show that they extract information about movement direction, as is evident from the similarity of response versus direction of movement profiles obtained with moving circle or moving random dots (Fig. $10 C)$. SGS1 neurons show insensitivity to the direction of movement regardless of stimulus geometry (Fig. 10D). We have not studied the response properties of SGS neurons located deep to the SGS1 layer in further detail; our twofold goal here was only to contrast SGS1 and SGS2 neuron response properties under the recording conditions of our study and to show that SGS2 neurons appeared very similar to those normally attributed to the visual SC.

\section{I S C U S S I O N}

Our results showed that cells in the rat superficial sublamina, SGS1, of the stratum griseum superificiale of the superior colliculus are characterized by brisk responses to flashing light spots and drifting gratings; they show orientation tuning to gratings and orientation-specific modulation of responses elic- 

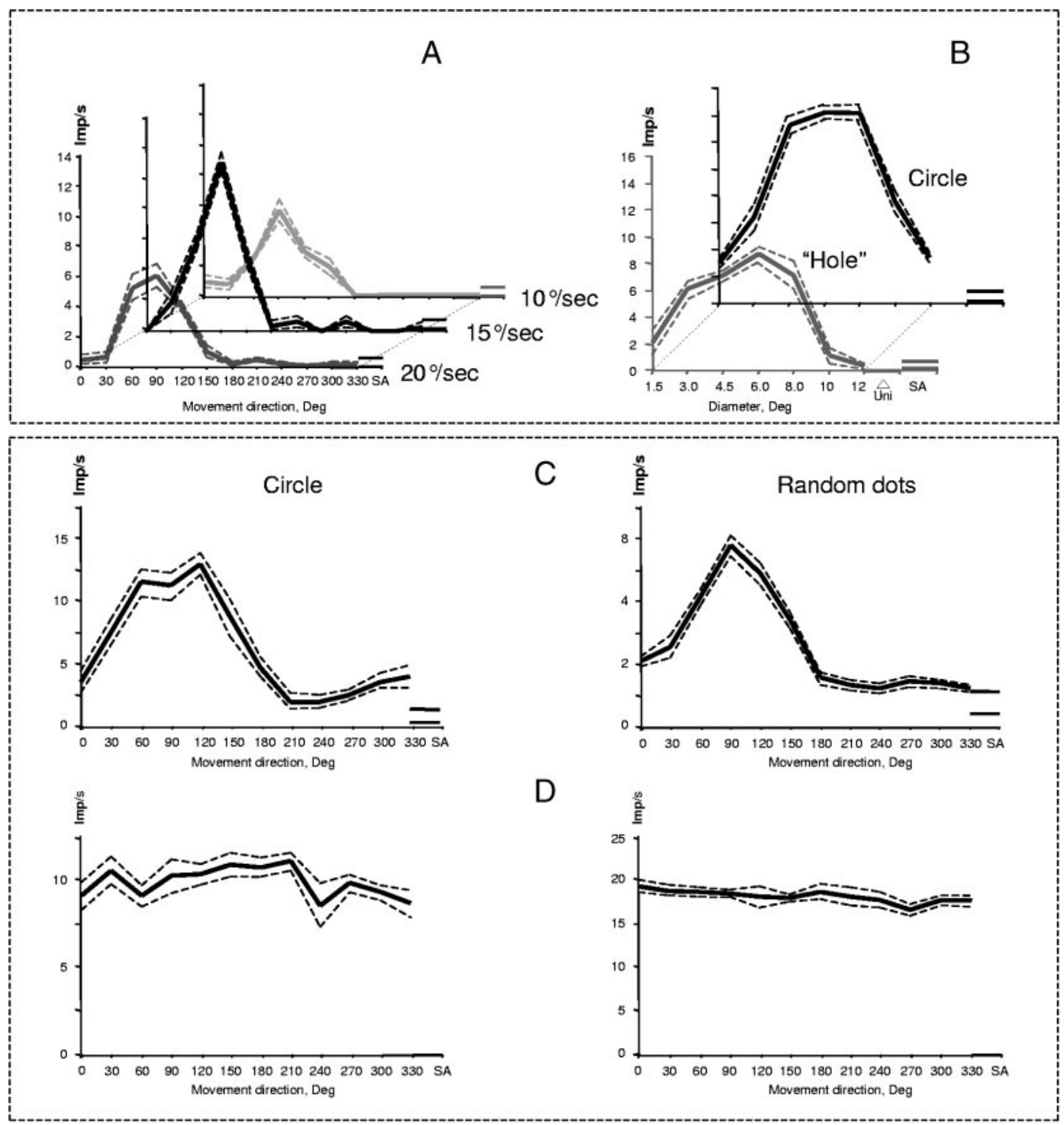

FIG. 10. $A$ and B, top panels: examples of responses recorded in the cell encountered around $100 \mu \mathrm{m}$ deeper than the lower border of SGS1. A: response vs. direction of movement of a circular light spot (diameter $3^{\circ}$ ) through the RF, with different movement velocities (indicated beside the graphs). Cell shows strong directional tuning and tuning to specific velocity of movement. $B$ : same cell shows responses both to flickering circles in the RF center and to the flickering whole screen except for the gray "hole," and no responses to a flickering uniform screen (indicated as "Uni" at the $x$-axis). Note the similarity of R vs. D profiles with both stimulus configurations; thus this cell showed an absence of antagonistic center-surround RF organization. $C$ and $D$, bottom panels: comparison of typical responses to movement recorded with the neuron encountered within SGS2, at the depth around $170 \mu \mathrm{m}$ below the SGS1 lower border (shown in $C$ ) and those recorded with the neuron within the SGS1 (shown in D). Left graphs: responses to moving light circle $3^{\circ}$ in diameter with varying the direction of the movement. Right graphs: responses to moving random dots with varying the direction of movement. Note strong directional selectivity in $C$ and an absence of directionality in $D$. Stimulus velocities (chosen to produce responses close to optimal): $15^{\circ} / \mathrm{s}$ in $C, 35 \%$ in $D$.

ited from the RF center by an annular grating surrounding it; they show complex response dynamics during presentation of successive cycles of periodic stimuli. Although the SGS1 neuron population is not homogeneous and a complete classification has yet to be done, we found some unique response properties common to a majority of SGS1 neurons.

Their most unexpected property, we believe, is that antagonistic center-surround, the dominating model of a neuron RF at early stages of visual processing, is inapplicable to the SGS1 neurons, while they process solely the immediate retinal input. First, SGS1 neurons cannot be assigned unambiguously to ON and/or off classes by their responses to flashing light spots. Furthermore, their $\mathrm{R}$ versus $\mathrm{D}$ profiles obtained with stimulation of the RF center cannot be a result of increasing spatial summation over the RF center, and of a fall caused by gradual involvement of an antagonistic periphery, as a summation model of RF postulates. We proved that performing the "complementary center-surround stimulation" tests with flashing and grating stimuli. As we show in the APPENDIX, if we assume a summating mechanism, then, applying the stimulus constituted by a "hole" of constant brightness and a flashing surround, or annulus grating, the curve of $\mathrm{R}$ versus $\mathrm{D}$ of the central "hole" or of the inner diameter of the annulus grating has to be a mirror image of that obtained with the first stimulus configuration, the flashing central spot, or grating patch, respectively. In fact, we found that these curves qualitatively repeated each other in case of flashing stimuli (Fig. 3); also, the $\mathrm{R}$ versus $\mathrm{D}$ curves recorded with annulus gratings (Fig. 7, $C-F$ ) 
were far from being mirror images of those recorded with grating patches of varying diameter. Thus responses of SGS1 neurons do not obey the necessary and sufficient condition the summation model of the RF imposes on R versus D curves; no fixed distribution of excitatory-inhibitory inputs and their interplay can account for responses of SGS1 neurons. Their responses are governed by more abstract rules than those dictated by a stationary spatial structure of the RF on which the stimulus with a particular spatial configuration projects. At least in the case of the Surround stimulus with a "hole," cell responses in the SGS1 are irrelevant to specific physical properties of the stimulus, such as brightness changes, in the RF center. Rather, the responses correlate with perception of an "object" in the restricted area of the visual field. Evidently, an "object" is represented by brightness differences in the RF's center and periphery, or just by the contour of the figure. To display such response features, neurons have to perform adaptable logical operations on their inputs. That makes the neurons we encountered in the SGS1 sublamina very distinctive from other neurons at early stages of visual processing, from the retina (Rodieck and Stone 1965) to the V1 (Sceniak et al. 2001), where the RFs can be described by a "difference of Gaussian" (DOG) model. On the other hand, perhaps, the DOG model is not as universal as we used to think, and that could be revealed by applying the "complementary center-surround stimulation" test to neurons in other brain visual centers.

The magnitude of the cell response to flashing stimuli or to grating patches is a function of the size of the "object", not a result of the summation a neuron performs on its unitary excitatory and inhibitory inputs. When tested with flashing solid circles or with flashing annulus presenting only the contour of the circle, the responses to both stimuli of the same diameter typically showed similar magnitudes. The responses to "contours" diminishes when the "object" in RF begins to lose its salience with thinning the "contour" of the shape.

An analogous explanation can be suggested for the observed orientation-specific center response modulation by the annulus grating presented in the RF surround. The response depends on how salient an "object" in the RF center is: if the peripheral grating is orthogonal to the central one, the central grating is most salient, there is no center response suppression, and even response facilitation may occur. When the orientation of peripheral grating approaches that of the center, the "object" in the RF center is masked by the peripheral grating, the size of which exceeds the optimum for producing neuron response, and maximal response suppression takes place.

Because the RFs of SGS1 neurons do not constitute an antagonistic center and surround, a definition of the RF size in the classical sense does not apply and the RF size of these neurons becomes ambiguous. One can suggest the size of RF as that of an "object" producing an optimal response. In the case of flashing stimuli, however, the same neuron typically showed different, though close, values (see Fig. 3) depending on the illumination level and sign of brightness transitions and on the way the "object" is shaped, by flashing center spot, by the "hole" in the flashing surround, or by the "contour" of the figure. Therefore other factors besides the "object" size can affect the maximal response at the response versus "object" size curves. To avoid the discrepancy and still be able to compare this response characteristic with that of classic neurons, we provided the "RF sizes" measured only with drifting grating patches (for population data see RESULTS). Their values were in a range with those recorded in the rodent SC in previous studies (in rat: Fortin et al. 1999; Fukuda and Iwama 1978; in hamster: Razak and Pallas 2005; Tiao and Blakemore 1976).

SGS1 neuron responses to alternating brightness of periphery in the presence of a blank circle in the RF center have something in common with responses recorded in the cat visual cortex (Rossi and Paradiso 1999; Rossi et al. 1996). These authors found that around $30 \%$ of cat VI neurons showed responses to this stimulus and proved that these neurons represent brightness information in the striate cortex because neuron responses showed several parallels with "induced brightness" perception. However, there are several important differences between responses to the "hole" stimulus of the neurons described in the cat cortex and those we found in rat SGS1. First, striate neurons responded robustly to a uniform field of varying luminance even when it significantly overlapped the RF, which is consistent with the implied role of the neurons in encoding brightness information. In SGS1, the neurons typically gave no response to the whole uniform screen with varying luminance; they also showed strong responses to grating stimuli, mostly in an orientation-specific manner. Thus SGS1 neurons do not encode brightness information per se. Second, striate neurons failed to respond to a flashing surround if the central blank "hole" was kept not gray, but black. This lack of responses correlates with the absence of brightness modulation in an "induced brightness" percept. We found that SGS1 neurons responded rather to the percept of an "object" in RF, not specifically to perceived brightness changes: neurons may respond to the flickering periphery around the "hole" irrespective of the sustained luminance of the "hole": gray, white, or black. Thus rat SGS1 and cat striate neurons show some similar response to this kind of stimulus, but the differences suggest that they might participate in different perceptual mechanisms. One caution is that comparisons cannot presently be made between cortex and SGS1 in the same animal, so species differences may confound regional comparisons.

OR tuning is widely supposed to be a "quintessentially cortical property" (Ferster and Miller 2000). This does not appear to be true, at least in the rat visual system, because we have shown here that most of the SGS1 neurons reveal robust OR tuning to gratings even in the absence of V1 input. Another property normally associated with the cortex, and especially with its role in figure-ground segregation, is well-known orientation-specific modulation of the RF center response from the RF periphery, stimulation alone of which produces no or weak response. SGS1 neurons also show such orientationspecific response modulation, when tested with grating stimuli, and respond to flickering "objects"; this offers further support for the hypothesis that SGS1 neurons may mediate figureground segregation.

The absence of any visual cortex influence on the responses of SGS1 neurons is in accord with anatomical studies in rats and many other species (in rat: Batista et al. 2003; Harvey and Worthington 1990; Lee et al. 2001; Lund 1969; Nakajima et al. 1996; in cat: Mize 1996; in tree shrew: Albano et al. 1978; Casagrande et al. 1972), which show that cortical afferents terminate mainly in deeper SGS2 and the optic fiber layer, whereas SGS1 contains sparse or no cortical input. All our 
recordings were made within the uppermost $100-150 \mu \mathrm{m}$ of the SGS1, but even in the deeper layer of the rodent SGS, the influence of descending cortical connections on SC response properties is minimal (Fortin et al. 1999; Razak and Pallas 2005; Rhoades and Chalupa 1978). Also, inactivation of V1 and V2 cortical areas in rat (Binns 1999; Binns and Salt 1996) imposes little effect even on directional tuning in SCS (generally assumed to be the most affected by cortical influence). Collectively these works indicate that cortical influence on SC does not shape response tuning in the SC, thus adding further affirmation of our observations that OR response tuning in SGS1 does not depend on V1 integrity.

The question is raised whether the orientation-specific responses are generated in the colliculus in parallel with the cortex or whether they have a common origin in the retina. Indeed, orientation-specific mechanisms have been found in studies of the cat retina (Shou et al. 2000). In our preliminary studies recording from ganglion cells in the rat retina (Girman and Lund 2005a), we found that some cells showed robust OR tuning to grating stimuli and orientation-specific center-surround interactions, similar to those described here and those reported in the visual cortex of a number of animals, including the rat (Girman et al. 1999). However, the cell types and complex synaptic patterns of the SGS1 could certainly provide a substrate for generation of the selective response properties detailed here. In particular are the horizontal cells that dendrites run for considerable distances across the SGS1 and receive optic input as well as making inhibitory synapses with other neurons (Houser et al. 1983; Langer and Lund 1974; Lund 1969). The dynamics of SGS1 neuron responses to grating stimuli, especially the sharpening of response tuning with consecutive grating periods, might suggest that the neurons perform complex spatiotemporal encoding of image features, possibly reflecting the activity of these complex synaptic arrays. The functional meaning of some aspects of the response dynamics is not clear. They may represent neuronal correlates of certain visual illusions that, in human observers, appear after rather prolonged repetitive visual stimulation with fixed gaze, the conditions closest to those used in animal experiments.

One can ask why the response properties we described in this paper, especially orientation specificity to gratings and RF organization revealed with flashing stimuli, are so different from those found in previous studies. We believe that the most superficial lamina of SC, the SGS1, actually has not yet been studied systematically. As far as we are aware, there are no studies aimed at the visual responses specifically in the SGS1. This seems rather surprising, taking into account the distinctive anatomy and electrophysiological clues ("juxtazonal potentials") associated with SGS1. A crucial issue is that it is necessary to use the very thin, sharp electrodes used here to isolate units in SGS1. With a coarse electrode penetrating the $\mathrm{SC}$, the pial membrane is depressed and then rebounds, so the electrode misses the very thin SGS1. Furthermore it is almost impossible to isolate single units in SGS1 with microelectrodes thicker than those used here. Nevertheless, some authors (Tiao and Blakemore 1976) have reported in rodents rarely encountered cells clearly different from the main SGS population. They responded to fast-moving stimuli (in the range 50$200 \%$ s, whereas a majority of SGS cells prefer low velocities), had extremely vigorous responses, and very low spontaneous activity, similar to those we found in SGS1, and it is possible that they were in fact SGS1 neurons. In cats (Waleszczyk et al. 1999) and monkeys (Wallace et al. 1997) the cells selective to fast-moving stimuli were encountered more frequently, perhaps because of simpler single-cell isolation in their anatomically different SGS1. Finally, we have applied a broader range of the tests and stimuli than that most previous studies of the visual SC used, including a variety of stimulus configurations and the gratings of varying orientation, and some of the unique properties defined here would not otherwise have been recognized.

Because we found that units deep to the SGS1 typically were selective to slow movement, showed strong directional selectivity, and responded poorly to grating stimuli, much as was described previously for SGS, we presume the unusual properties recorded at the surface of the SC do in fact represent a distinct sublamina with respect to visual processing. It should be noted that when recording deep to the SGS1 and applying the stimuli not used in previous studies, we found more response complexity than previously recognized.

Response specificity to movement parameters (velocity, direction) rather than to stimulus orientation is a property most commonly associated with the SC. This has been shown in rodents, cats, and in primates (Dreher and Hoffmann 1973; Fukuda and Iwama 1978; Horwitz and Newsome 2001; Razak and Pallas 2005; Wallace et al. 1996, 1997) and most likely represents a property of SGS2 neurons. By contrast, it appears that SGS1 neurons generally are not tuned, or tuned very poorly, to the velocity or direction of movement. Although a few show evidence of directionality, moving random dots (presenting pure movement in the absence of an orientation component) do not produce direction-selective responses and, presented in the RF periphery, impose no direction-specific modulation of responses elicited from the RF center. Thus the SGS1 layer is not likely to be involved in processing of movement information for visual centering or saccadic behaviors.

SGS1 neurons extract differences of illumination across the visual field, as well as orientation clues to perform figureground segregation in the image. Such complex properties of SGS1 neurons make the SC a good candidate for mediating "blindsight"- the unconscious visual capability that can be identified after geniculo-striate system ablation (Cowey 2004). Up to now, such a role for the SC has been doubted on the grounds of its supposedly very stereotyped visual-processing capabilities. Our results show that at least for the rat this is not the case. Whether this neuronal layer of cortex-like response properties is present in SCS1 of more visually advanced animals remains to be seen.

\section{A P P E N D IX}

Suppose a neuron performs a spatial summation over some (any) spatial distribution of unitary excitatory and inhibitory inputs within its RF and these inputs have some (any) spatial profile of weight functions. With this assumption, the sum of the neuron responses to each of two partial stimulus configurations has to be equal to the response produced by the stimulus for which spatial configuration is a combination of these two partial stimulus configurations, if other stimulus parameters are the same. Thus if the RF is positioned somewhere on a display screen and three stimulus configurations (see Fig. 2D) and corresponding responses (R) are 


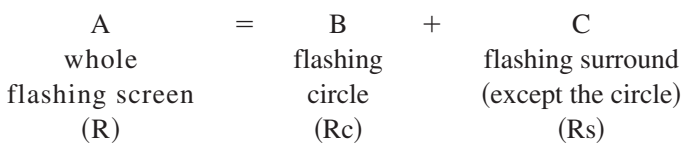

then

$$
\mathrm{R}=\mathrm{Rc}+\mathrm{Rs}
$$

to brightness transition eliciting response and this must be true for any diameter $\mathrm{D}$ of the circle. These considerations are applicable to the responses to drifting grating patches and annuli shown in Fig. 7

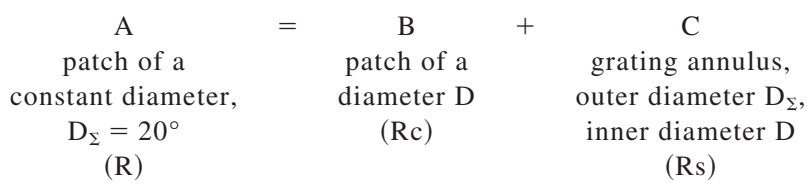

and they lead to the same Eq. Al as above. This equation shows that, if the curves $\operatorname{Rc}(\mathrm{D})$ and $\operatorname{Rs}(\mathrm{D})$ intersect, then at an intersection point

$$
\operatorname{Rc}(D)=\operatorname{Rs}(D)=R / 2
$$

In a differential form $E q$. Al is

$$
0=\mathrm{dRc}(\mathrm{D}) / \mathrm{dD}+\mathrm{dRs}(\mathrm{D}) / \mathrm{dD}
$$

and thus

$$
\mathrm{dRc}(\mathrm{D}) / \mathrm{dD}=-\mathrm{dRs}(\mathrm{D}) / \mathrm{dD}
$$

Thus Rc and Rs as functions of a diameter D are mirror images of one another. This constitutes the "complementary center-surround stimulation" test: the bisymmetry, relative to R/2, is the necessary and sufficient condition the curves $\operatorname{Rc}(\mathrm{D})$ and $\operatorname{Rs}(\mathrm{D})$ have to obey if a neuron performs a spatial summation of its inputs.

Obviously, if the curve bisymmetrical to $\operatorname{Rc}(\mathrm{D})$ drops to or below the $x$-axis in some range of $\mathrm{D}$, the $\mathrm{Rs}(\mathrm{D})$ must be equal to zero in this range of $\mathrm{D}$ (spiking rate cannot be negative-the cell is inhibited) and vice versa. In case the response to the whole flashing screen is absent $(\mathrm{R}=0)$, which was observed in a majority of recorded SGS1 neurons, and if $\mathrm{Rc} \neq 0$ in some range of $\mathrm{D}$, then Rs must be absent in this range of $\mathrm{D}$. In the opposite case of Rs $\neq$ 0 , the same is true for Rc. Therefore Rc and Rs cannot be present together.

The preceding conclusions are based on an assumption that a neuron performs spatial summation of its unitary inputs. The $\mathrm{R}$ versus D curves we obtained with SGS1 neurons applying the "complementary center-surround stimulation" test with flashing or drifting grating stimuli clearly diverged from those predicted by summation model of RF. Therefore this model does not apply to the studied SGS1 neurons.

\section{A C K N O W L E D G M EN T S}

We thank Dr. J. S. Lund for critically reading this manuscript and Dr. J. B. Levitt for extensive discussion. We are grateful to Dr. G. Long for technical editing the manuscript.

\section{G R A N T S}

This work was supported by National Eye Institute Grant EY-14038 and by unrestricted grants to Moran Eye Center and Casey Eye Institute by Research to Prevent Blindness, New York. Dr. R. Lund is a recipient of a Research to Prevent Blindness Senior Investigator Award.

\section{REFERENCES}

Albano JE, Humphrey AL, Norton TT. Laminar organization of receptivefield properties in tree shrew superior colliculus. J Neurophysiol 41: 11401164, 1978.

Batista CM, Carneiro K, de Bittencourt-Navarrete RE, Soares-Mota M, Cavalcante LA, Mendez-Otero R. Nitrergic dendrites in the superficial layers of the rat superior colliculus: retinal afferents and alternatively spliced isoforms in normal and deafferented animals. J Neurosci Res 71: 455-461, 2003.

Binns KE. The synaptic pharmacology underlying sensory processing in the superior colliculus. Prog Neurobiol 59: 129-159, 1999.

Binns KE, Salt TE. Corticofugal influences on visual responses in cat superior colliculus: the role of NMDA receptors. Vis Neurosci 13: 683-694, 1996.

Boyer JL, Harrison S, Ro T. Unconscious processing of orientation and color without primary visual cortex. Proc Natl Acad Sci USA 102: 16875-16879, 2005.

Casagrande VA, Harting JK, Hall WC, Diamond IT, Martin GF. Superior colliculus of the tree shrew: a structural and functional subdivision into superficial and deep layers. Science 177: 444-447, 1972.

Cirone J, Salt TE. Group II and III metabotropic glutamate receptors contribute to different aspects of visual response processing in the rat superior colliculus. J Physiol 534: 169-178, 2001.

Cowey A. The 30th Sir Frederick Bartlett lecture. Fact, artefact, and myth about blindsight. Q J Exp Psychol A 57: 577-609, 2004.

Cunningham TJ, Lund RD. Laminar patterns in the dorsal division of the lateral geniculate nucleus of the rat. Brain Res 34: 394-398, 1971.

Dean P. Visual pathways and acuity hooded rats. Behav Brain Res 3: 239-271, 1981.

Dreher B, Hoffmann KP. Properties of excitatory and inhibitory regions in the receptive fields of single units in the cat's superior colliculus. Exp Brain Res 16: 333-353, 1973.

Ferster D, Miller KD. Neural mechanisms of orientation selectivity in the visual cortex. Апnи Rev Neurosci 23: 441-471, 2000.

Fortin S, Chabli A, Dumont I, Shumikhina S, Itaya SK, Molotchnikoff S. Maturation of visual receptive field properties in the rat superior colliculus. Brain Res Dev Brain Res 112: 55-64, 1999.

Fukuda Y, Iwama K. Visual receptive-field properties of single cells in the rat superior colliculus. Jpn J Physiol 28: 385-400, 1978.

Girman SV, Lund RD. Functional properties of neurons in the superficial layer in rat superior colliculus. Program No. 507.8. 2005 Abstract Viewer/ Itinerary Planner. Washington, DC: Society for Neuroscience, 2005a. Online.

Girman SV, Lund RD. Complex response properties of ganglion cells in the rat retina. Program No. 976.8. 2005 Abstract Viewer/Itinerary Planner. Washington, DC: Society for Neuroscience, 2005b. Online.

Girman SV, Lund RD. Neural correlates of perceptual figure-ground segregation in rat superior colliculus. Program No. 240.12. 2006 Abstract Viewer/ Itinerary Planner. Atlanta, GA: Society for Neuroscience, 2006, Online.

Girman SV, Sauve Y, Lund RD. Receptive field properties of single neurons in rat primary visual cortex. J Neurophysiol 82: 301-311, 1999.

Girman SV, Wang S, Lund RD. Time course of deterioration of rod and cone function in RCS rat and the effects of subretinal cell grafting: a light- and dark-adaptation study. Vision Res 45: 343-354, 2005.

Gonzalez F, Perez R, Alonso JM, Labandeira-Garcia JL, Acuna C. Responses of visual single cells in the superior colliculus of the albino rat to bright bars. Arch Ital Biol 130: 249-261, 1992.

Harvey AR, Worthington DR. The projection from different visual cortical areas to the rat superior colliculus. J Comp Neurol 298: 281-292, 1990.

Holscher C, Schnee A, Dahmen H, Setia L, Mallot HA. Rats are able to navigate in virtual environments. J Exp Biol 208: 561-569, 2005.

Horwitz GD, Newsome WT. Target selection for saccadic eye movements: direction-selective visual responses in the superior colliculus. J Neurophysiol 86: 2527-2542, 2001.

Houser CR, Lee M, Vaughn JE. Immunocytochemical localization of glutamic acid decarboxylase in normal and deafferented superior colliculus: evidence for reorganization of gamma-aminobutyric acid synapses. $J \mathrm{Neu}$ rosci 3: 2030-2042, 1983.

Langer TP, Lund RD. The upper layers of the superior colliculus of the rat: a Golgi study. J Comp Neurol 158: 418-435, 1974.

Lashley K. The mechanisms of vision. XV. Preliminary studies of the rat's capacity for detailed vision. J Gen Physiol 18: 123-193, 1938.

Lee PH, Schmidt M, Hall WC. Excitatory and inhibitory circuitry in the superficial gray layer of the superior colliculus. J Neurosci 21: 8145-8153, 2001.

Lund RD. Synaptic patterns of the superficial layers of the superior colliculus of the rat. J Comp Neurol 135: 179-208, 1969.

McIlwain JT. Cat superior colliculus: extracellular potentials related to W-cell synaptic actions. J Neurophysiol 41: 1343-1358, 1978.

Mize RR. Neurochemical microcircuitry underlying visual and oculomotor function in the cat superior colliculus. Prog Brain Res 112: 35-55, 1996. 
Nakajima J, Saito N, Kani K, Maeda T. Morphologic analysis of rat retino-collicular neuron terminals containing monoamine oxidase. Brain Res Bull 40: 209-217, 1996.

Nekovarova T, Klement D. Operant behavior of the rat can be controlled by the configuration of objects in an animated scene displayed on a computer screen. Physiol Res 55: 105-113, 2006.

Prusky GT, West PW, Douglas RM. Behavioral assessment of visual acuity in mice and rats. Vision Res 40: 2201-2209, 2000.

Razak KA, Pallas SL. Neural mechanisms of stimulus velocity tuning in the superior colliculus. J Neurophysiol 94: 3573-3589, 2005.

Rhoades RW, Chalupa LM. Functional properties of the corticotectal projection in the golden hamster. J Comp Neurol 180: 617-634, 1978.

Rodieck RW, Stone J. Analysis of receptive fields of cat retinal ganglion cells. J Neurophysiol 28: 832-849, 1965.

Rossi AF, Paradiso MA. Neural correlates of perceived brightness in the retina, lateral geniculate nucleus, and striate cortex. J Neurosci 19: 61456156, 1999.

Rossi AF, Rittenhouse CD, Paradiso MA. The representation of brightness in primary visual cortex. Science 273: 1104-1107, 1996.
Sceniak MP, Hawken MJ, Shapley R. Visual spatial characterization of macaque V1 neurons. J Neurophysiol 85: 1873-1887, 2001.

Shou T, Wang W, Yu H. Orientation biased extended surround of the receptive field of cat retinal ganglion cells. Neuroscience 98: 207-212, 2000.

Stein BE, Jiang W, Stanford TR. Multisensory integration in single neurons of the midbrain. In: Handbook of Multisensory Integration, edited by Calvert G, Stein BE. Cambridge, MA: MIT Press, 2004, p. 243-264.

Tiao YC, Blakemore C. Functional organization in the superior colliculus of the golden hamster. J Comp Neurol 168: 483-504, 1976.

Waleszczyk WJ, Wang C, Burke W, Dreher B. Velocity response profiles of collicular neurons: parallel and convergent visual information channels. Neuroscience 93: 1063-1076, 1999.

Wallace MT, McHaffie JG, Stein BE. Visual response properties and visuotopic representation in the newborn monkey superior colliculus. J Neurophysiol 78: 2732-2741, 1997.

Wallace MT, Wilkinson LK, Stein BE. Representation and integration of multiple sensory inputs in primate superior colliculus. J Neurophysiol 76: 1246-1266, 1996.

Wurtz RH, Optican LM. Superior colliculus cell types and models of saccade generation. Curr Opin Neurobiol 4: 857-861, 1994. 